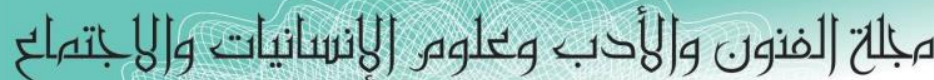

Journal of Arts, Literature, Humanities and Social Sciences

ISSN online: 2414 - 3383

ISSN print: 2616 - 3810

العدد (40) تهوز - يوليو 2019

\title{
تأثثير دورات الإيقاع الحيوي الأساسية عند تسجيل الأهداف في دورة الألعاب الاولمبية لكرة القدم للرجال- ريو دي جاتيرو 2016
}

\author{
د. حسين علي كنبار \\ مدير قسم منح إجازة الاستثمار \\ الهيئة الوطنية للاستثمار \\ بغداد ـ العراق باق \\ ايميل: dkinbar@gmail.com
}

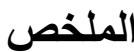

هدفت هذه الدر اسة إلى تحديد تأثير دورات الإيقاع الحيوي الأساسية و علاقتها في تسجيل الأهداف للاعبين الذين

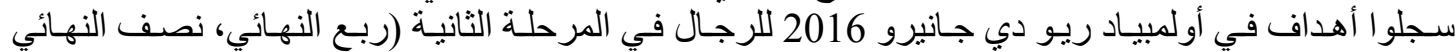

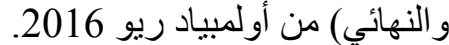

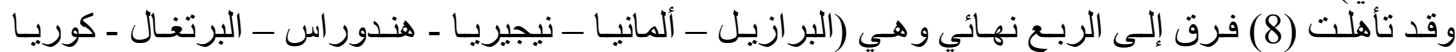

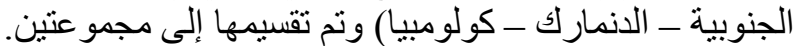

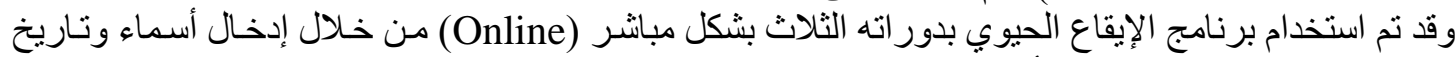

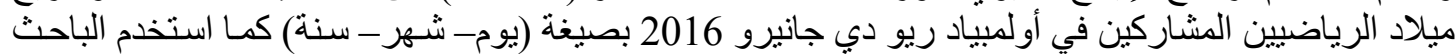

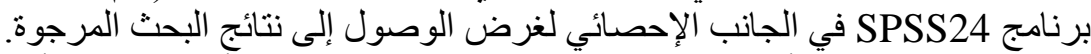

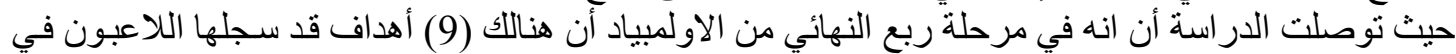
هذه المرحلة، منهم (7) لاعبين وقعو افي الجانب الإيجابي من دورات الإيقاع الحيوي بنسبة (78\%).

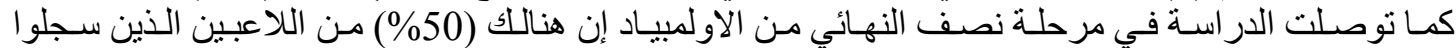
الأهداف قد وقعو ا في الجانب الإيجابي من دورات الإيقاع الحيوي، بعدد أهداف بلغ (4) أهداف من عدد الأهداف

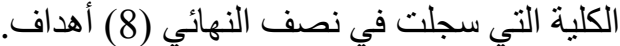
أما في المباريات النهائية في دورة الألعاب الاولمبية 2016 فقد تم تسجيل (7) أهداف منها (67٪) من الهابئ الاعبين

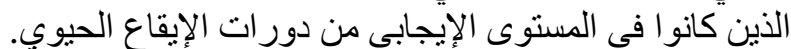

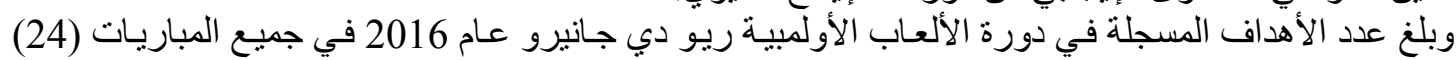

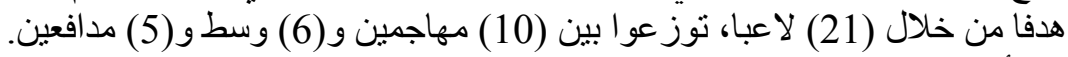

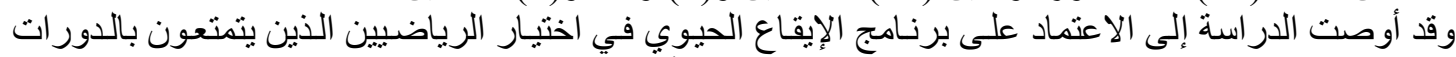

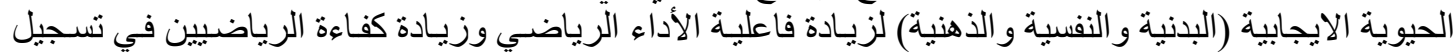

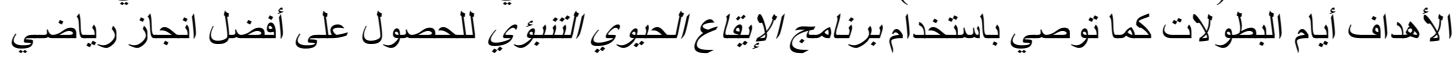




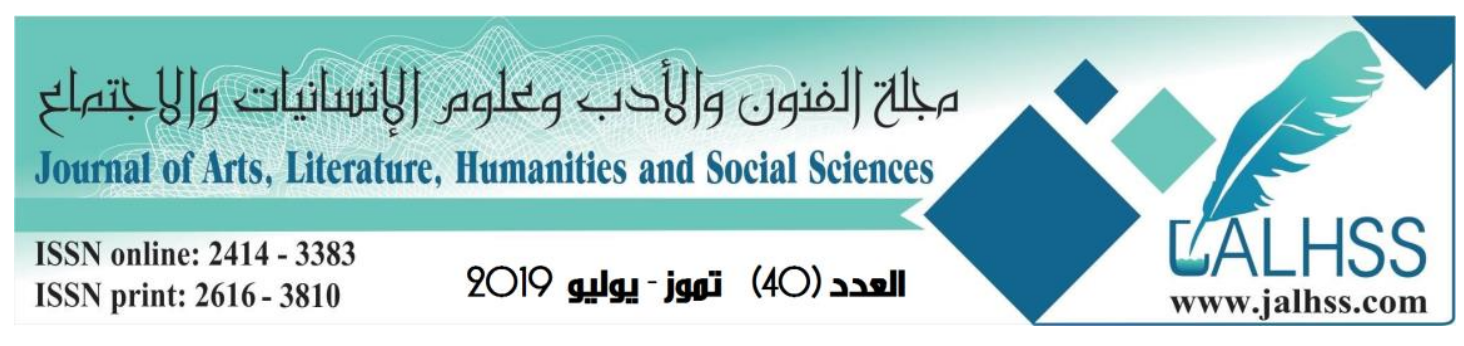

\title{
The Effect of Basic Biorhythm Cycles When Goals Scoring at the Olympics Rio de Janeiro 2016 for Men Soccer
}

\author{
Dr. Hussain A. Kinbar \\ Manager of the issuing investment licenses Section \\ National Investment Commission \\ Baghdad - Iraq \\ dkinbar@gmail.com
}

\begin{abstract}
The aim of this study is to determine the impact of biorhythm cycles on the players who have scored goals. It was the use of the Rio de Janeiro 2016 Olympics men's soccer in second phase (Quarterfinal, Semifinal and Final) matches.

The researcher used the program SPSS 24 for the purpose of reaching a desired search results where the study found that players in the quarterfinal of the champion have been scored (9) goals of them (7) players have fallen into the positive side of the biorhythm cycles by $(78 \%)$.

In the semifinal of the champion have scored positive players who amused goals $(50 \%)$ of the total number of goals scored semifinal (8) goals.

The final matches in the 2016 Olympics has been scored (7) goals of which (67\%) of the players who were in the positive level of biorhythm.

Number of purposeful scored goals in the Olympics, Rio de Janeiro has reached 2016 (24) goals by (21) players were divided among (10) players as (FW), (6) players as (M) and (5) players as (D).

The main conclusions and recommendations:

- The rate of participation of positive biorhythm of the players who scored goals at the Rio de Janeiro 2016 Olympics show the importance of studying the bio state of players.

- Sports need to adopt biorhythm program in the selection of the players the most appropriate in the starting line-up for the teams exactly at the day of the match, especially the offensive players and for selection the best players at the day of the match, to increase the probability of scoring goals, and predict the best sports performance of players.

- The players who fall into the negative level of biorhythm prefers not to involve them in important matches.
\end{abstract}




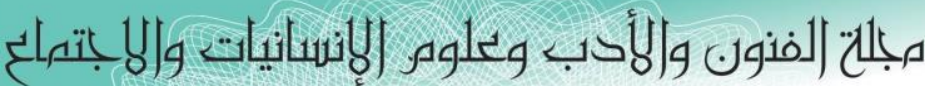

Journal of Arts, Literature, Humanities and Social Sciences

ISSN online: 2414 - 3383

ISSN print: 2616 - 3810

\section{العدد (4O) تموز - يوليو 2019}

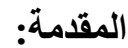

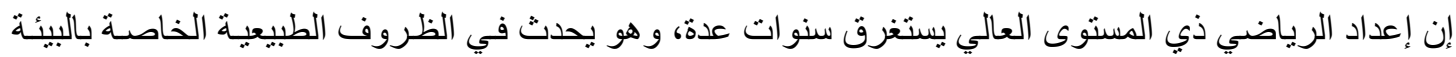

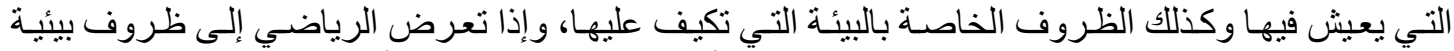

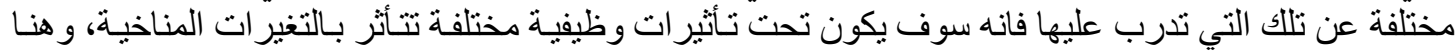

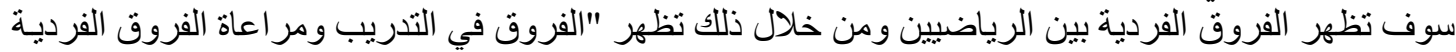

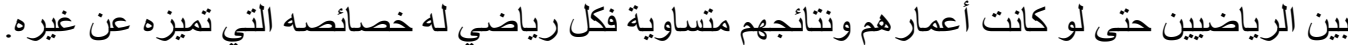

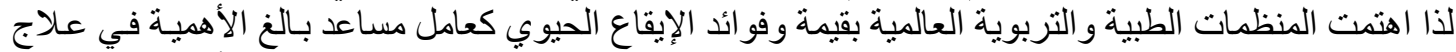

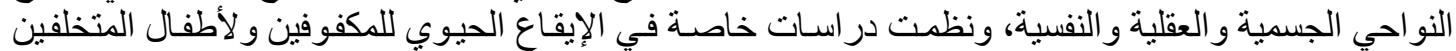

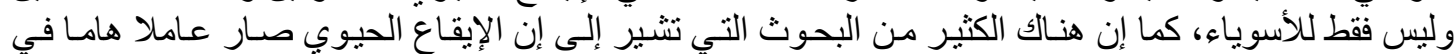

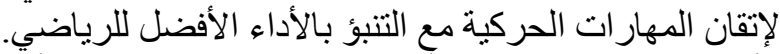

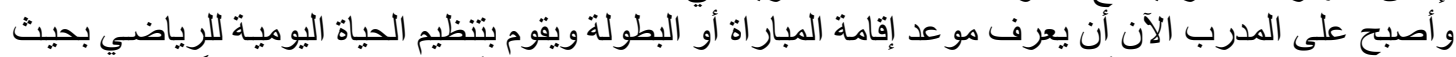

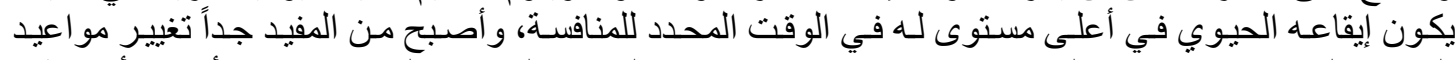

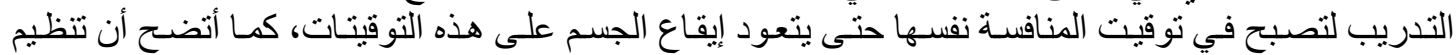

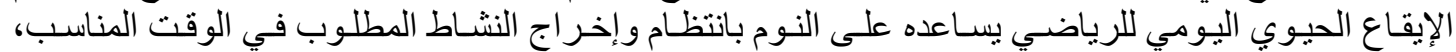

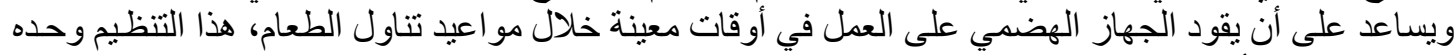
يحقق للرياضي أفضل الظروف لتنظيم حالته التنريبية و التنافسية.

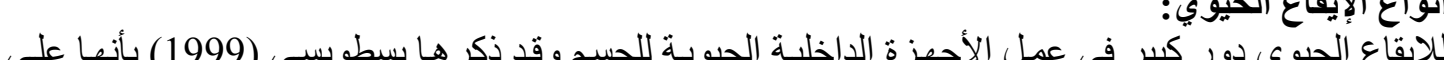
لإنواعاع الإيقاع الحيوي:

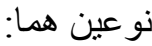
1- الإيقاع الحيوي الداخلي: إن الإيقاع الحيوي اليومي يغير حو الي (50) وظيفة فسيولوجية للأجهزة جسم

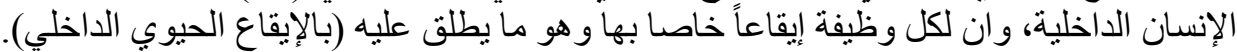

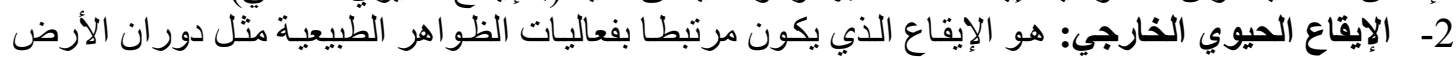

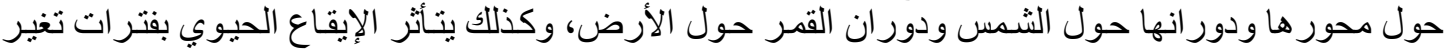

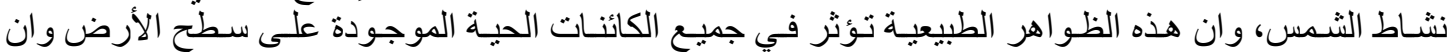

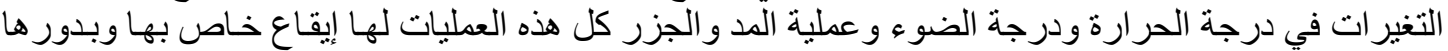

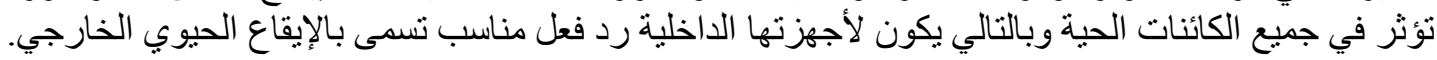

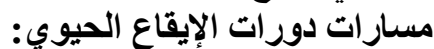

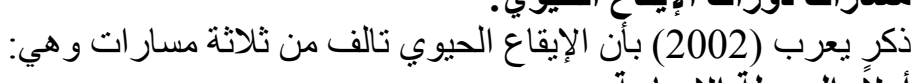

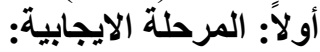

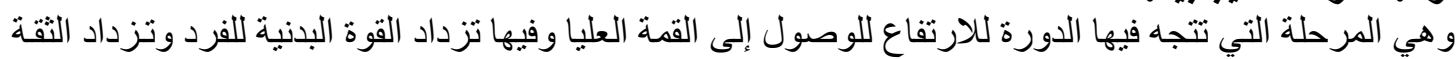

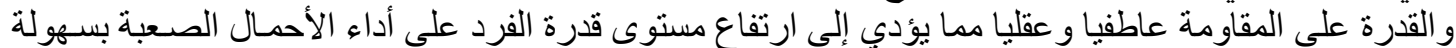
نسبياً وبالتالي نتوقع تحقيق المقارئ نتائج ايجابية.

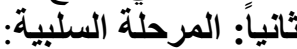

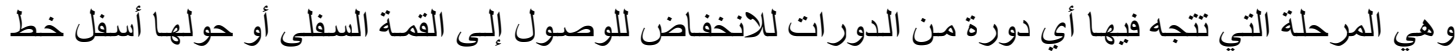

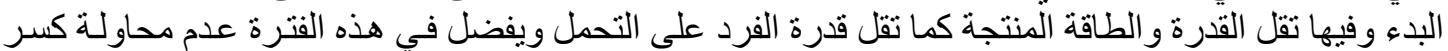

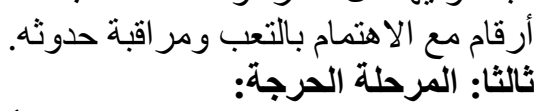

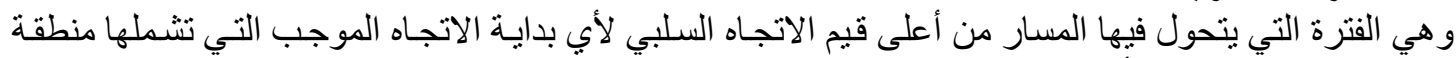

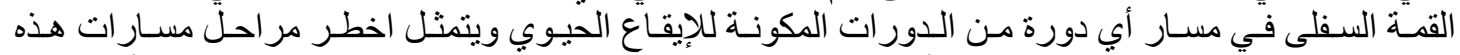

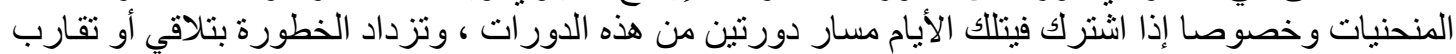

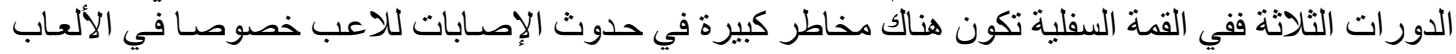




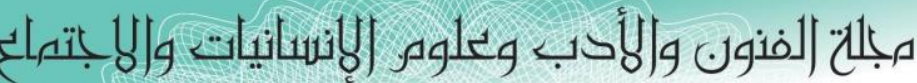

Journal of Arts, Literature, Humanities and Social Sciences

ISSN online: 2414 - 3383

ISSN print: 2616 - 3810

\section{العدد (4O) توز - يوليو 2019}

HALHSS

التي تحتاج إلى تركيز عقلي مثل الجمناستلك ولمو انع وذللك لان تفاصيل التكنيك مرتبطـة ومصـاحبه بقدرة الفرد

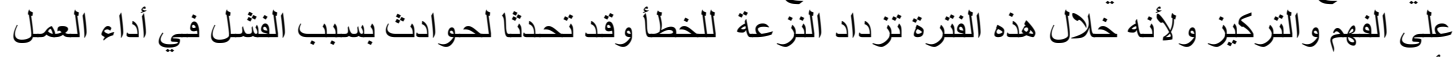

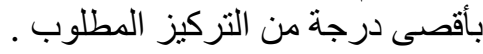

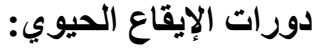

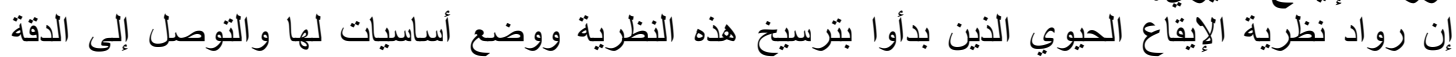

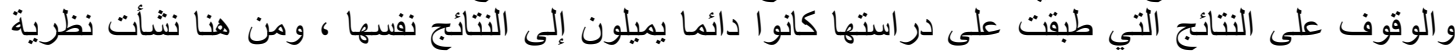

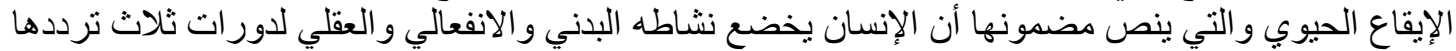

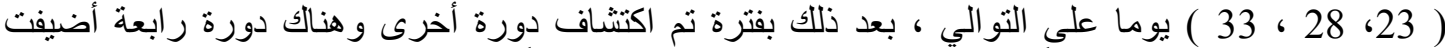

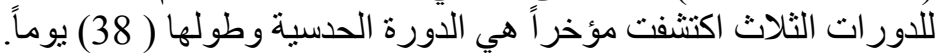

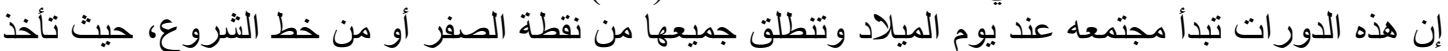

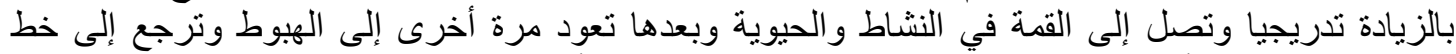

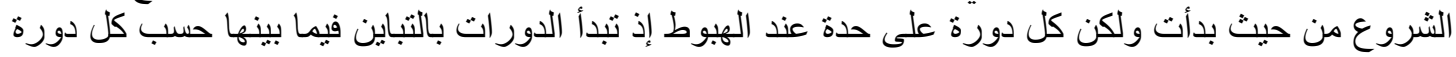

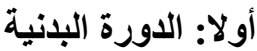

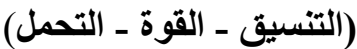

تستمر الدورة البدنية لمدة 23 يومًا وتؤثر عادةً على العو امل البدنية على سبيل المثال: ـ التنسيق بين البد و العين

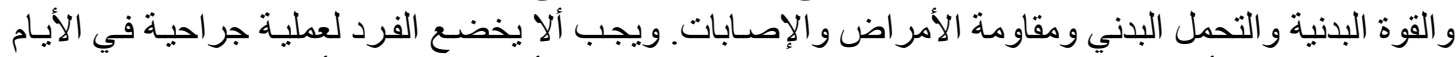

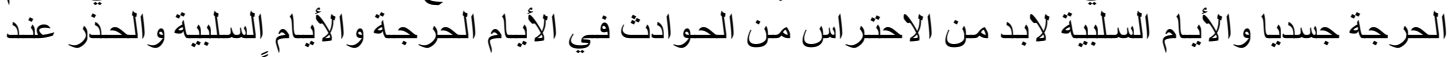

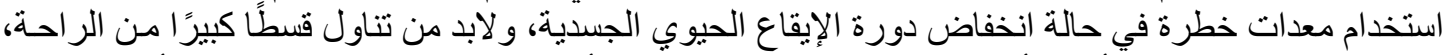

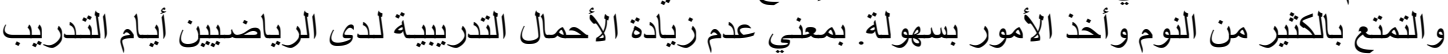

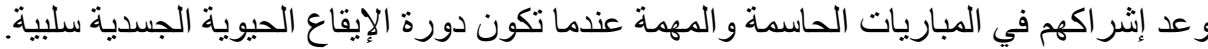

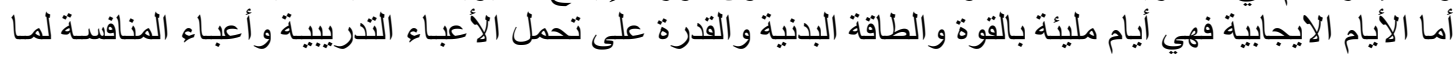

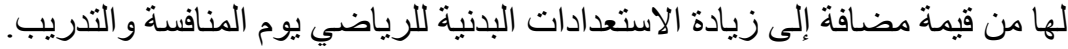

ثانياً: الدورة العاطفية

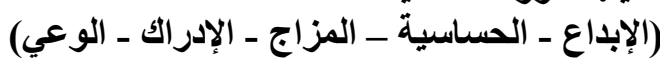

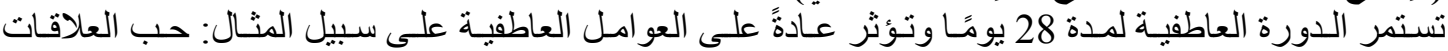

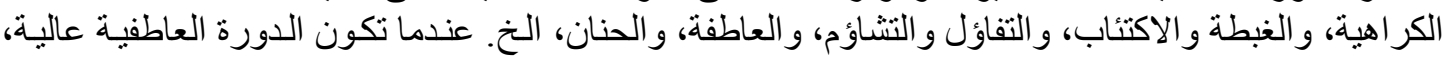

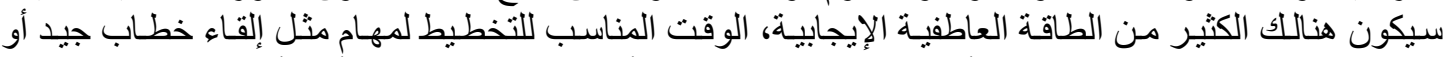

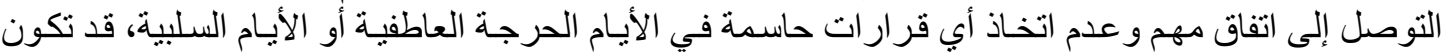

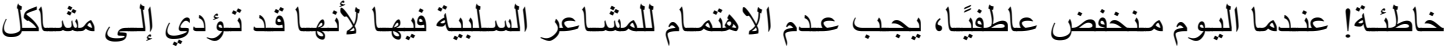
و انفعالات سلبية تؤثر أثناء الأداء و لا بد من استثمار اليوم الأكثر إيجابية في اتخاذ القرارات الحاسمة.

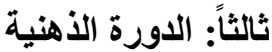

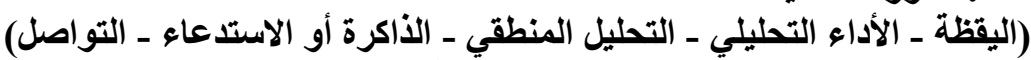

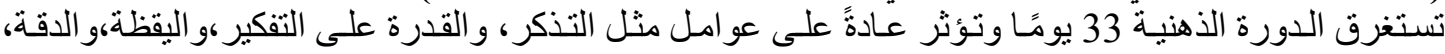

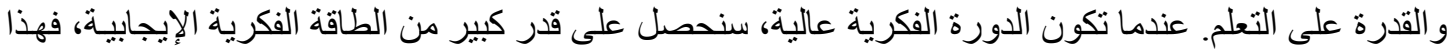

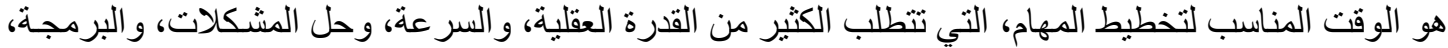

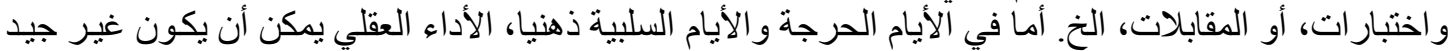

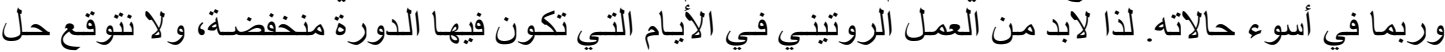
مشكلة ما عندما تكون دورة الإيقاع الحيوي منخفضة الرئة 


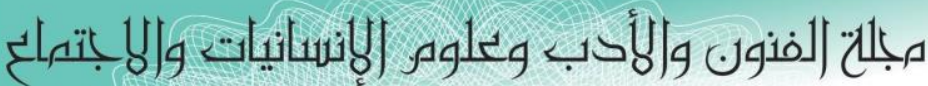

Journal of Arts, Literature, Humanities and Social Sciences

ISSN online: 2414 - 3383

ISSN print: 2616 - 3810

\section{العدد (40) تموز - يوليو 2019}

مشكلة الدر اسة ماسة

يو اجه الكثير من اللاعبين صعوبة تسجيل الأهداف عند التهديف نحو المرمى ومن مسافات مختلفة، ولذللك يحاول

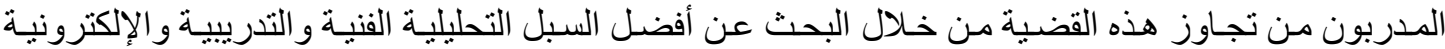

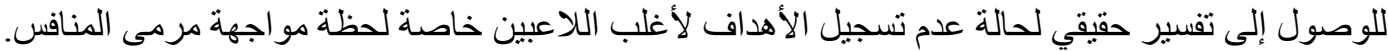
وقد يجد بعض المدربون علة قلة الأهداف في بعض المباريات بالرجو إلهو إلى الجانب الخططي أو المهاري و الفني

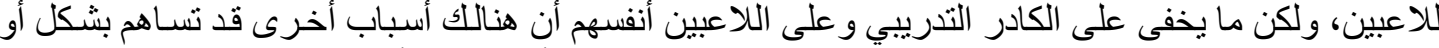

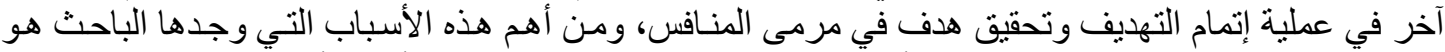

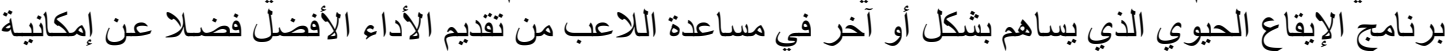

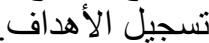

إن عملية تسجيل الأهداف تتعلق بالكثير من المعطيات (البدنية والنفسية و الذهنية) لحظة اتخاذ القرار بالتهديف و هذا وقت جدا قليل و اقل من أجز اء الثانية أثناء المباريات، لذا فعملية قياس أو تحديد أهم المتغيرات الت لحظة تسجيل

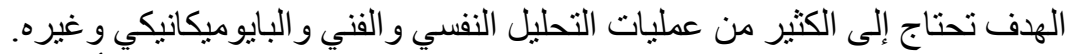

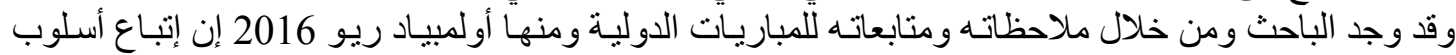

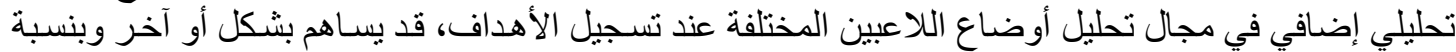

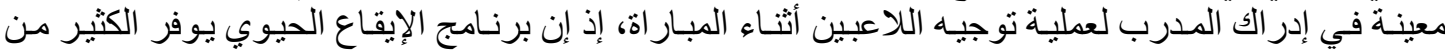

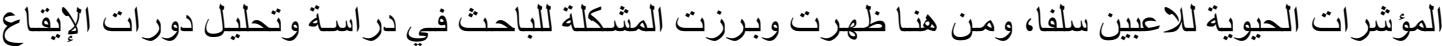
الحيوي الإيجابية اللاعبين الذين سجلوا الأهداف في أولمبياد ريو دير في جانيرو 2016.

أهداف الار اسةة 1. التعـرف على دور ات الإيقاع الحيويـة الأساسـية و علاقتهـا بتسـجيل الأهداف في أولمبيـاد ريـو دي جـانيرو .2016 2. معرفة أهم الدورات تأثير ا على عينة البحث عند تسجيل الأهداف في الألعاب الأولمبيـة في ريو دي جـانيرو .2016

فرضيات الار اسة 3. إن لدور الدرات الإيقاع الحيوي الأسـاسية تأثنير اً في تسـيل الأهداف في الألعـاب الأولمبيـة في ريو دي جـانيرو .2016 4. وجـود تبـاين في دور ات الإيقـاع الحيـوي الأساسية (البدنيـة و النفسية و الذهنيـة) عند تسـجيل الأهداف في الألعاب الأولمبية في ريو دي دي دانيرو 2016.

أهمية الار استة

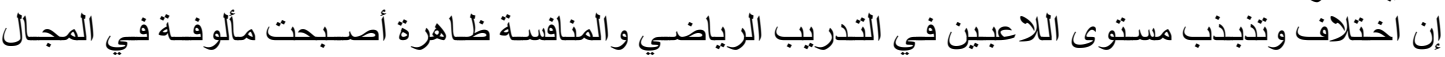
الرياضي عامة وفي مجال كرة القدم الأكثر شعبية وجماهيرية، وللرجية فوع إلى إلى أسباب تذبذب مستوى اللاعبين فيما

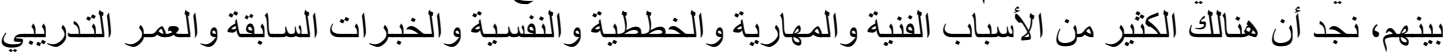

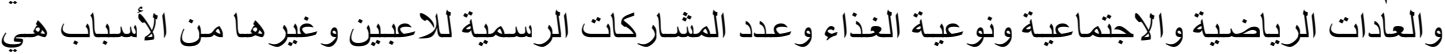

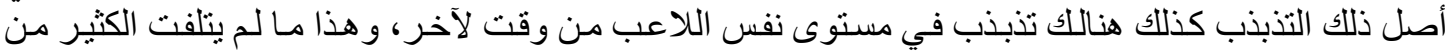

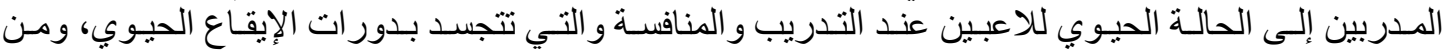

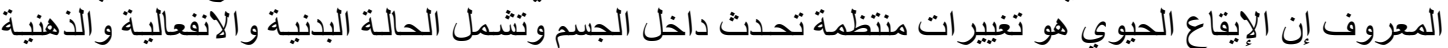

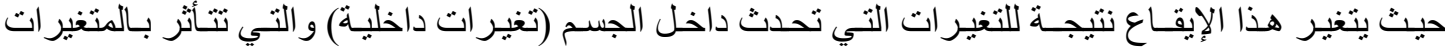
الخارجيـة (الإيقاع الخارجي) المحيط بالإنسان.

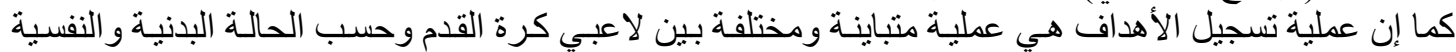

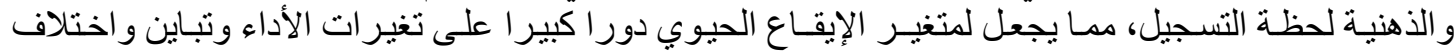




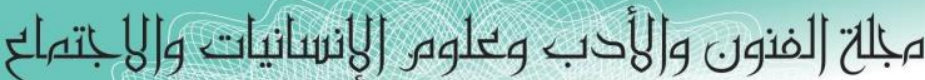

Journal of Arts, Literature, Humanities and Social Sciences

ISSN online: 2414 - 3383

ISSN print: 2616 - 3810

\section{العدد (4O) توز - يوليو 2019}

المستوى من آن إلى آخر لذلك فإن الاهتمام بدر اسة نظرية الإيقاع الحيوي يسـاعد المدرب على التوقـع و التتبؤ

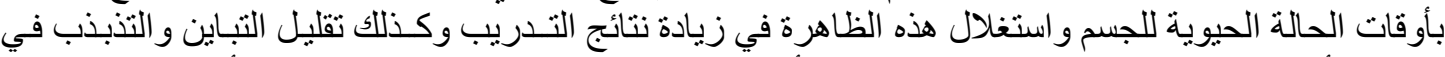

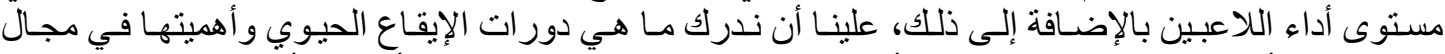

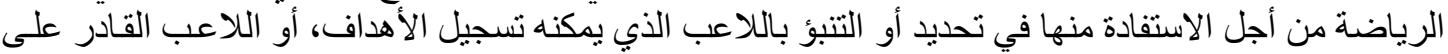

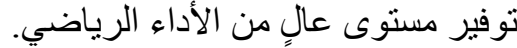
وتتلخص أهمية الاراسة فيما يلي: - الآدياضي الرياضي

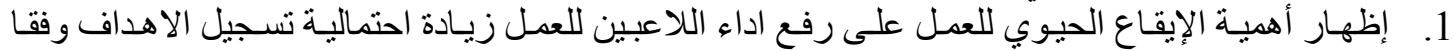

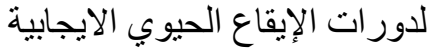

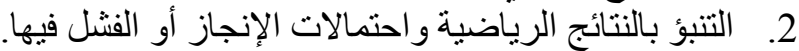

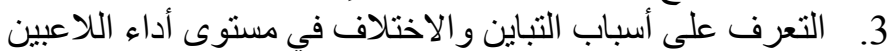

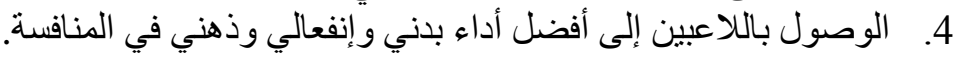

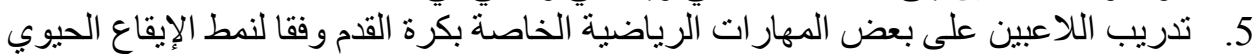

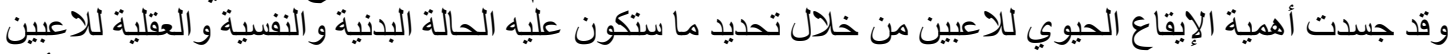

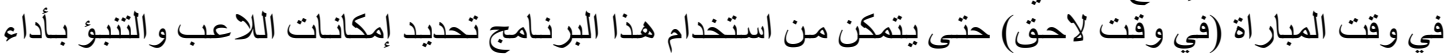

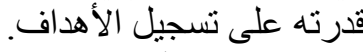

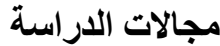
المجال البشري: هدافي أولمبياد ريو 2016.

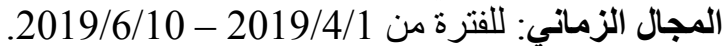
المجال المكاني: روسيا حيث أقيمت بطولة كأس العالم 2018.

الارسات السابقة و المشابهة:

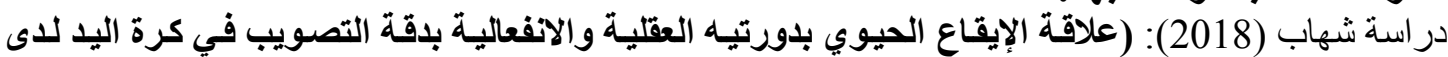

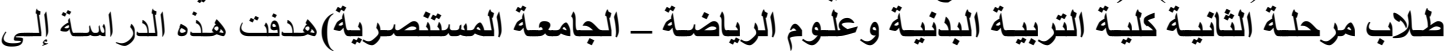

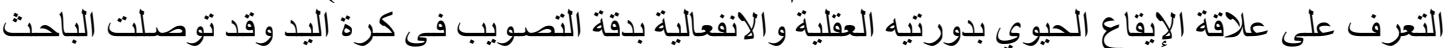

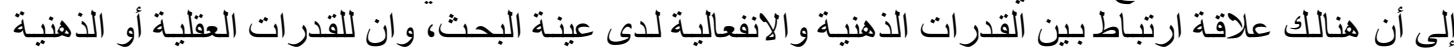

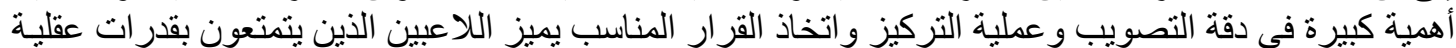
عالية.

دراسة كنبار (2016) بعنو ان (دراسة تحليلية مقارنة لمستوى أداء المنتخب الوطني العراقي في خليجي (22)

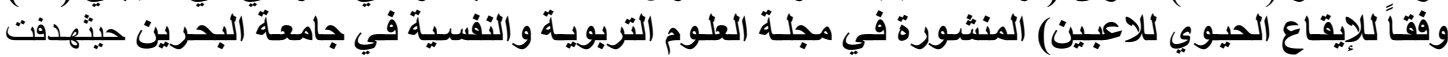

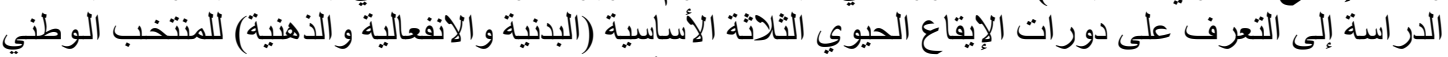

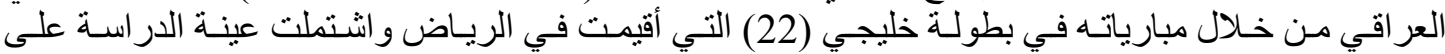

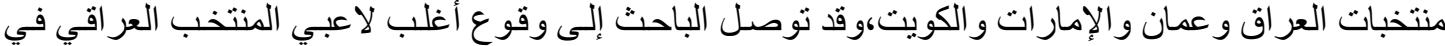

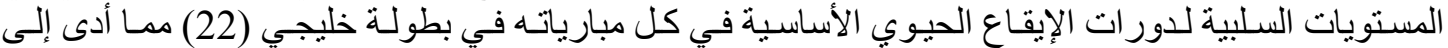

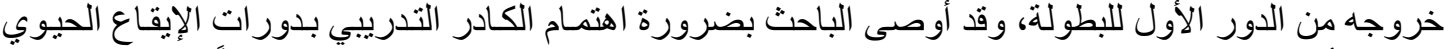

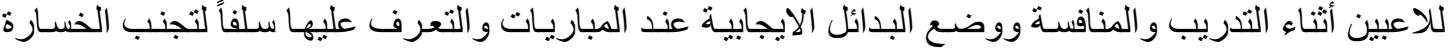

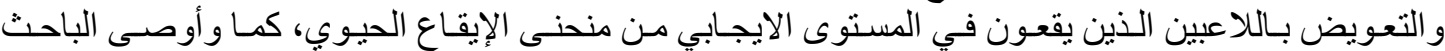

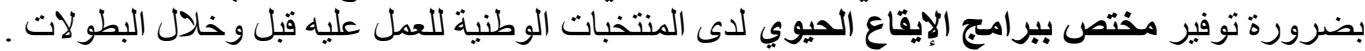

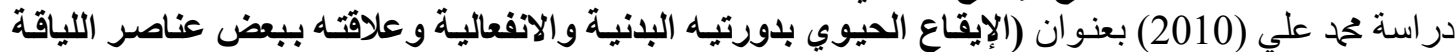

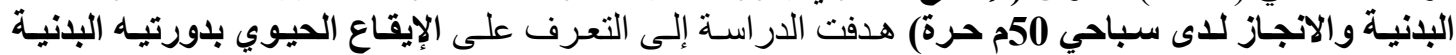

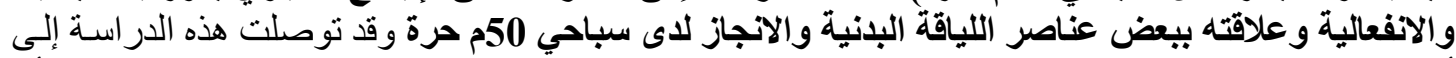

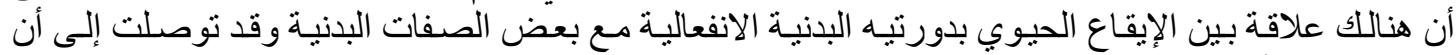
التعرف على تأثير الإيقاع الحيوي للاعبين يساعد المدرب على رفع مستوى الانجاز الرياضي. الإني. 


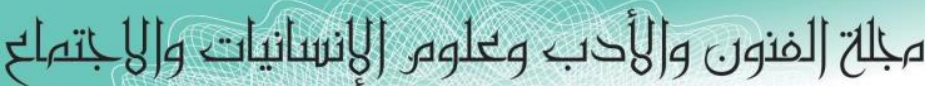

Journal of Arts, Literature, Humanities and Social Sciences

ISSN online: 2414 - 3383

ISSN print: 2616 - 3810

\section{العدد (4O) توز - يوليو 2019}

قام خطـاب (2009) بدر اسـة " تأثير الإيقاع الحيوي النفسي على بعض المهارات النفسية والأداء المهاري

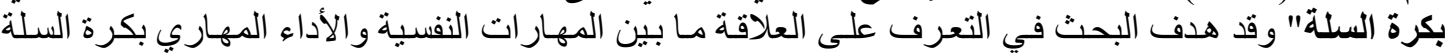

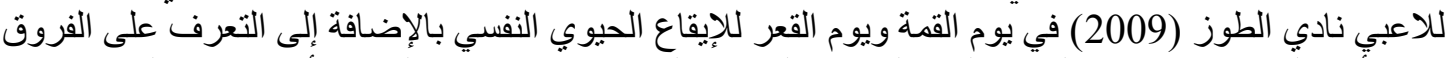

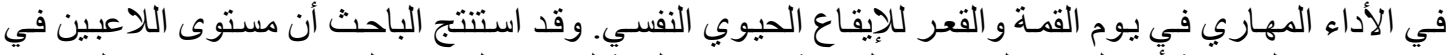

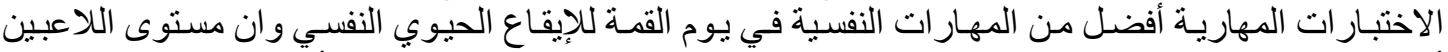

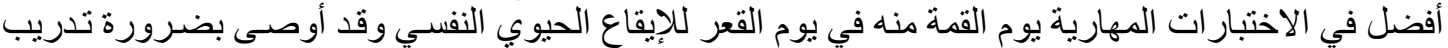

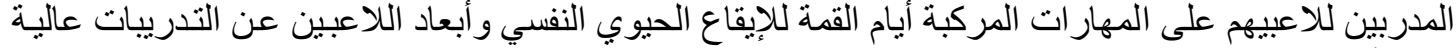
الثندة أيام القعر للإيقاع الحيو العيوي النفسي.

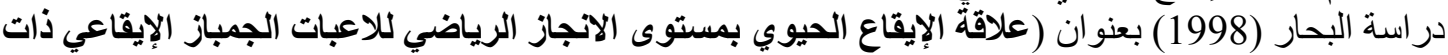

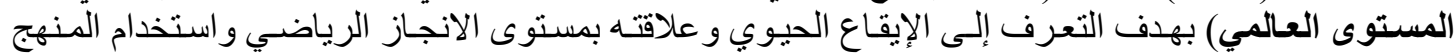

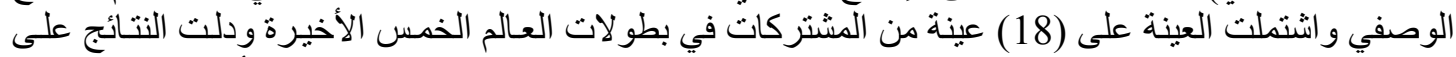

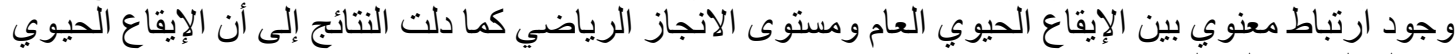
كان له القدرة على الثتبؤ بمستوى الإنجاز.

منهجية الاراسة وإجراءاتها الميدانية

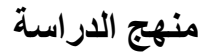

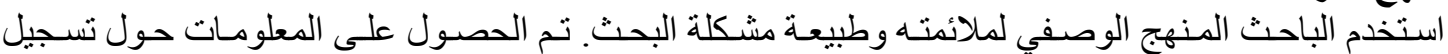

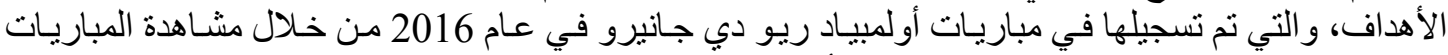

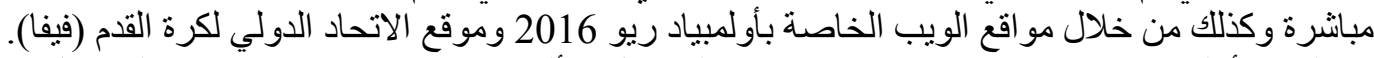

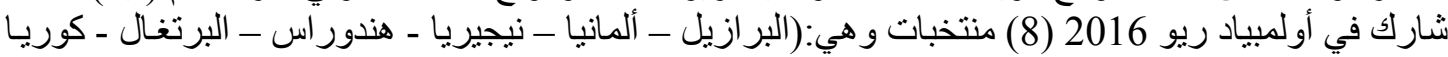
الجنوبية - الدنمارك - كولومبيا) عينة الاراسة ع البنة اختار الباحث عينة البحث بالطريقة العمدية وقد تمثلت بهدافي أولمبياد ريو 2016 المقامة في البرازيل و عددهم

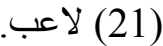
الأجهزة والأدوات المستخدمة في الاراسة:

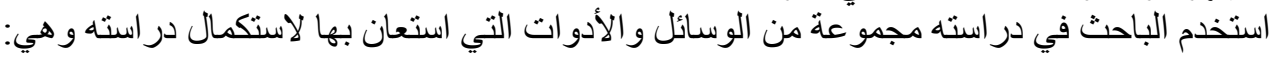

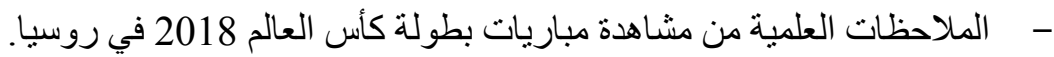
- - مالمادر العربيةوالأجنبية. - - - مالبرمجيات و التطبيقات المستخدمة بالحاسوب. - برنامج قياس الإيقاع الحيوي على الثبكة العنكبوتية (online).

الأداة المستخدمة في الاراسة:

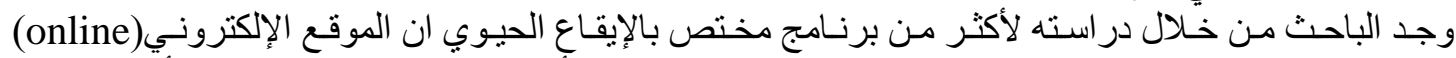
(http://www.procato.com/biorhythm)

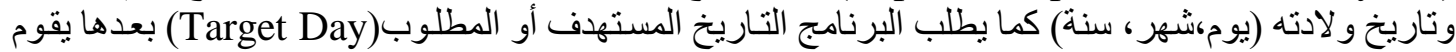

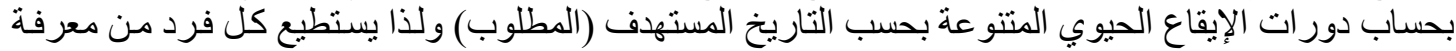
إيقاعه الحيوي في الماضي و الحاضر و المستقبل. الوسائل الإحصائية استخدم البأحث برنامج الإكسل (Excel) و البرنامج الإحصائي SPSS. 


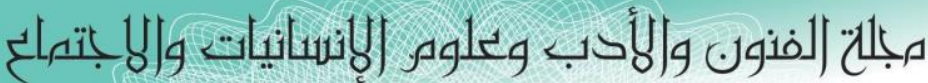

Journal of Arts, Literature, Humanities and Social Sciences

ISSN online: 2414 - 3383

ISSN print: 2616 - 3810

\section{العدد (4O) توز - يوليو 2019}

عرض وتحليل نتائج الإيقاع الحيوي لبطولة أولمبياد ريو 2016.

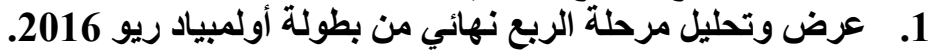
أقيمت مباريات دور الربع نهائي أولمبياّد ريو 2016 في يوم السبت 2016/8/13 وقد أعَّد الباحث جدول بأسماء الهدافين لهذا الدور مع قيم دور اتهم الحيوية الثلاثة ومعدل تلك الدور الثيات وكما في الجدول (1).

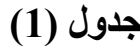

يوضح هدافي مرحلة الربع نهائي أولمبياد ريو 2016 وقيم دوراتهم الحيوية ومعدل تلك الدورات

\begin{tabular}{|c|c|c|c|c|c|c|c|}
\hline المنتخب & المعدل & الذهنية & النفسية & البدنية & مركز اللعب & عدد الأهداف & الاسم \\
\hline ألمانيا & $\% 83$ & $\% 69$ & $\% 90$ & $\% 89$ & دفاع & 1 & فيليب ماكس \\
\hline نيجيريا & $\% 46$ & $\% 46$ & $\% 78$ & $\% 14$ & وسط & 1 & ميكل نـون أوبــي \\
\hline ألمانيا & $\% 20$ & $\% 100-$ & $\% 78$ & $\% 82$ & دفاع & 1 & ماثياسجينتير \\
\hline ألمانيا & $\% 17$ & $\% 87-$ & $\% 97$ & $\% 40$ & هجوم & 1 & دافي سيلك \\
\hline البر ازيل & $\% 16$ & $\% 62$ & $\% 78-$ & $\% 63$ & هجوم & 1 & نليفا \\
\hline نيجيريا & $\% 6$ & $\% 95$ & $\% 90-$ & $\% 14$ & وسط & 1 & أمينو عمر \\
\hline ألمانيا & $\% 3$ & $\% 76$ & $\% 22$ & \%89- & وسط & 1 & جنابري \\
\hline هندور اس & $\% 17-$ & $\% 54-$ & $\% 43$ & $\% 40-$ & هجوم & 1 & ألبرثإليس \\
\hline \multirow[t]{2}{*}{ البر ازيل } & \%79- & $\% 87-$ & \%97- & $\% 52-$ & وسط & 1 & و الاس أوليفر ا \\
\hline & & & & & & 9 & المجموع \\
\hline
\end{tabular}

من الجدول (1) يتضـح أن عدد الذين سجلو ا أهداف (9) لاعبين من أربعـة منتخبات وهي وهي (البر ازيل و ألمانيا

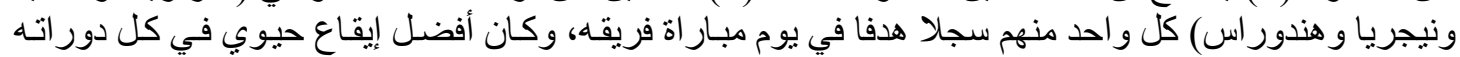

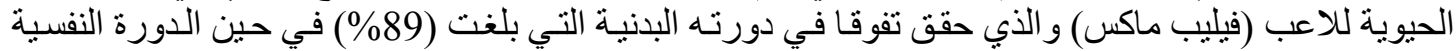

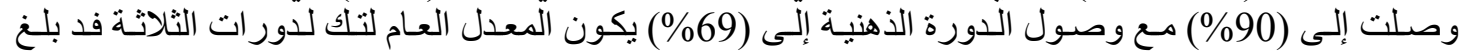

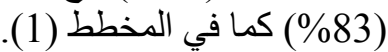

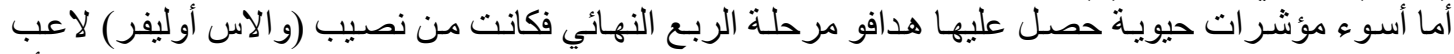

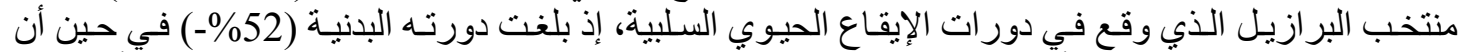

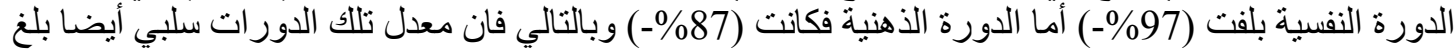

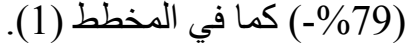
كما إن من الملاحظ في الجدول (1) بأن مر اكز اللعب قد تنوعت بين هدافي هذه المرحلـة بين مهاجم ووسط ومدافع. 


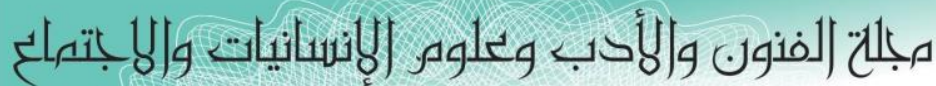
Journal of Arts, Literature, Humanities and Social Sciences

ISSN online: 2414 - 3383

ISSN print: 2616 - 3810

\section{العدد (4O) تموز - يوليو 2019}

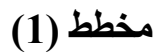

توضيح نسبة مشاركة الها|فين في معدل دوراتهم الحيوية للاور ربع نهائي أولمبياد ريو 2016

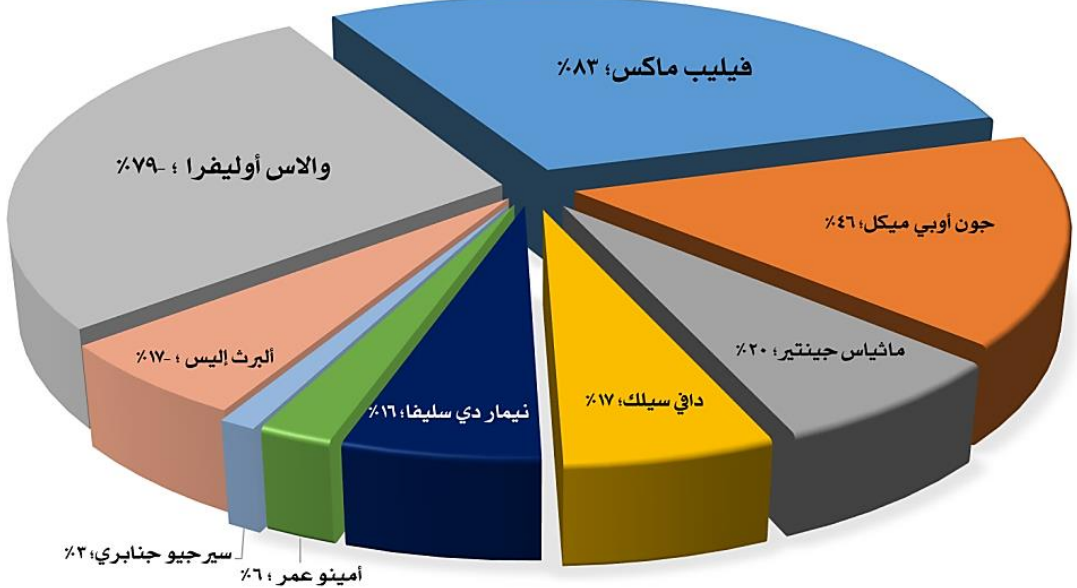

2. عرض الوسط الحسابي والانحراف المعياري للمرحلة الربع نهائي من بطولة أولمبياد ريو 2016.

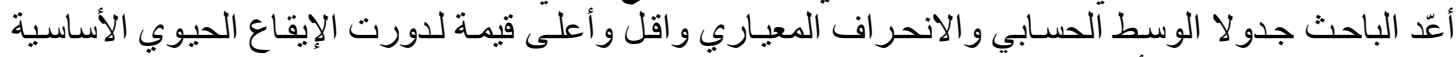

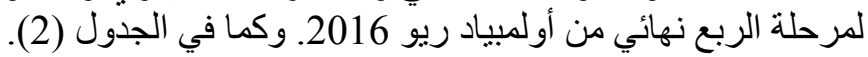

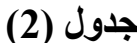

الوسط الحسابي والانحراف المعياري واقل و أعلى قيمة لاورت الإيقاع الحيوي الأساسية للربع نهائي من

أولمبياد ريو 2016

\begin{tabular}{|c|c|c|c|c|c|}
\hline المعدل & الاهنية & النفسية & البدنية & الأهداف & \\
\hline 9 & 9 & 9 & 9 & 9 & عدد الأهداف \\
\hline 10.56 & 2.22 & 15.89 & 13.44 & & الوسط الحسابي \\
\hline 44.05 & 81.80 & 81.65 & 62.45 & & المعياري \\
\hline$\% 79-$ & $\% 100-$ & $\% 97-$ & $\% 89-$ & & اقل قيمة \\
\hline$\% 83$ & $\% 95$ & $\% 97$ & $\% 89$ & & اعلى قيمة \\
\hline
\end{tabular}

3. عرض نسبة المعدل العام لاورات الإيقاع الحيوي لأفضل هدافي مرحلة الربع نهائي من أولمبياد ريو اعد الباحث جدو لا يتضمن أفضل الإيقاعات الحيوية لأفضل ثلاثة هدافين في مرحلة الربع نهائي من أولمبياد ريو

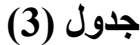

2016 وكما في الجدول (3).

يوضح دورات الإيقاع الحيوي لأفضل هدافي مرحلة الربع نهائي من أولمبياد رو 2016

\begin{tabular}{|c|c|c|c|}
\hline المنتخب & المعدل العام للاورات & مركز اللعب & الاسم \\
\hline ألمانيا & $\% 83$ & مهاجم & فيليب ماكس \\
\hline نيجريا & $\% 46$ & وسط & جون أوبي ميكل \\
\hline ألمانيا & $\% 20$ & دفاع & ماثيسجنتر \\
\hline
\end{tabular}




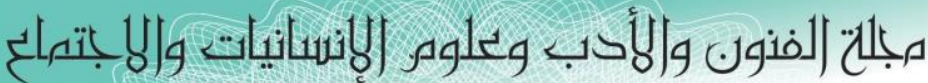

Journal of Arts, Literature, Humanities and Social Sciences

ISSN online: 2414 - 3383

ISSN print: 2616 - 3810

\section{العدد (4O) توز - يوليو 2019}

LALHSS

WWw.jalhss.com

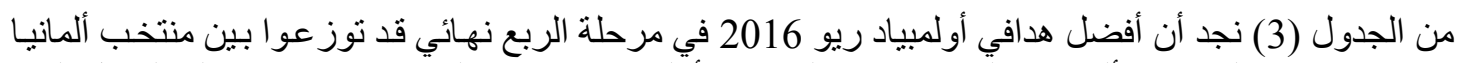

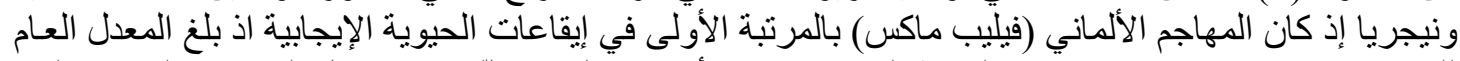

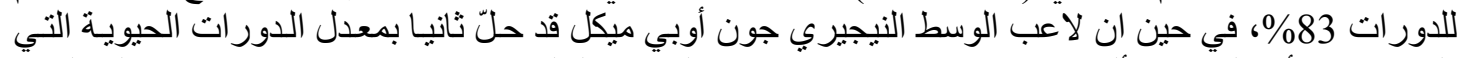

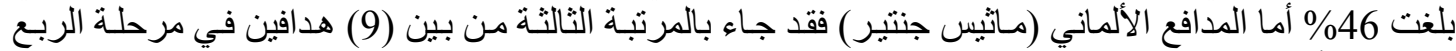

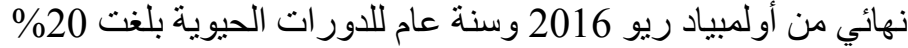

4. عرض نسبة دورات الإيقاع الحيوي للمنتخبات في مرحلة الربع نهائي من بطولة أولمبياد ريو الإيو 2016.

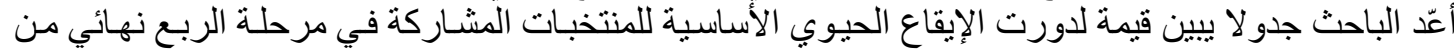

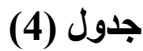

أولمبياد ريو 2016. وكما في الجدول (4).

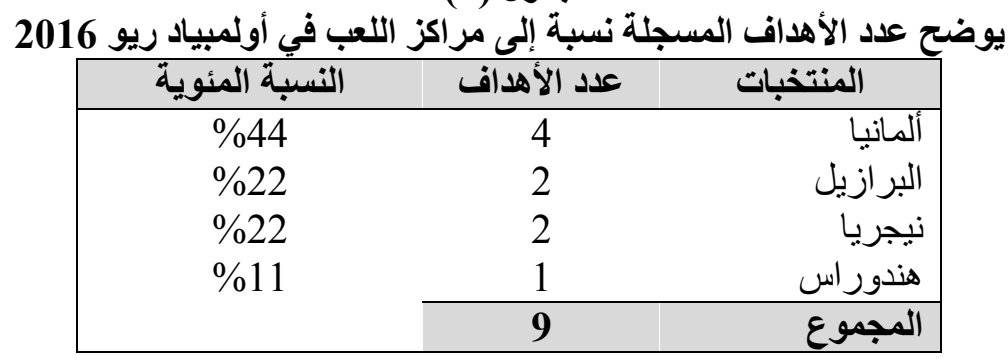

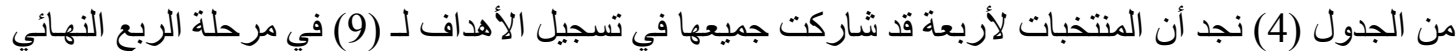

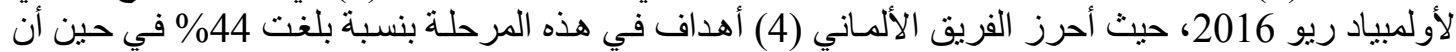

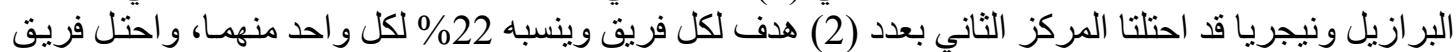

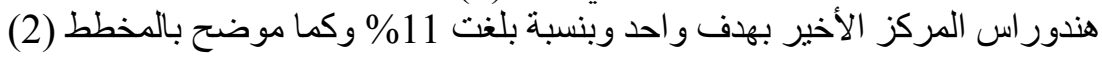

مخطط (1) موران

توضيح نسبة مشاركة الها|فين في معدل دوراتهم الحيوية للاور ربع نهائي أولمبياد ريو 2016

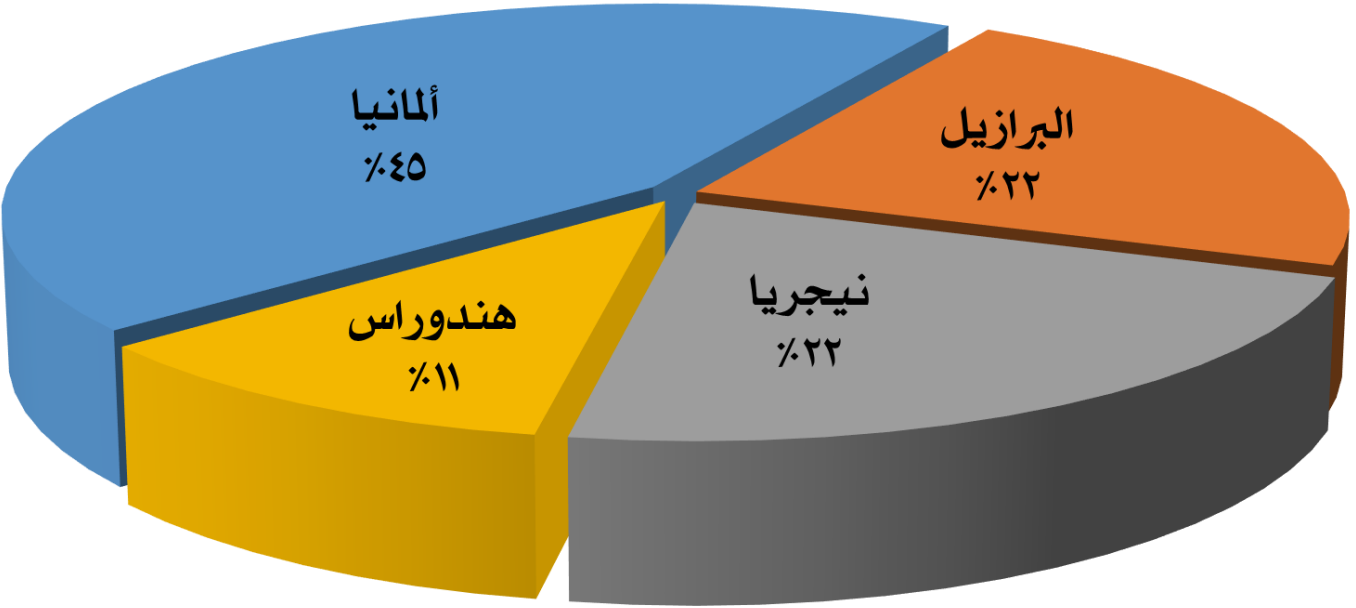

5. عرض مستويات دورات الإيقاع الحيوي الايجابية لربع نهائي من بطولة أولمبياد ريو 2016.

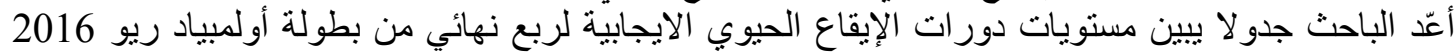
وكما في الجدول (5). 


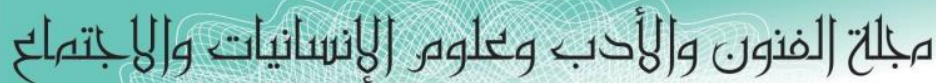

Journal of Arts, Literature, Humanities and Social Sciences

ISSN online: 2414 - 3383

ISSN print: 2616 - 3810

\section{العدد (4O) توز - يوليو 2019}

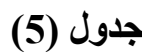

\begin{tabular}{|c|c|c|}
\hline النسبة المئوية & عدد اللاعبين & مستوى معدل دورات الإيقاع الحيوي \\
\hline$\% 78$ & 7 & المستوى الإيجابي لمعدل الدورات الحيوية \\
\hline$\% 22$ & 2 & المستوى السلبي لُمعدل الدورات الحيوية \\
\hline$\% 100$ & 9 & المجموع \\
\hline
\end{tabular}

من الجدول (5) نجد أن المستوى الإيجابي لدورات الإيقاع الحيوي لمرحلة الربع نهائي من أولمبياد ريو 2016

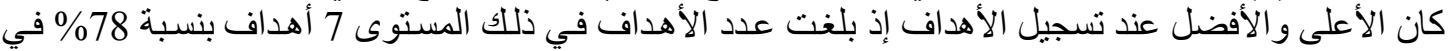
حين أن المستوى السلبي لدور الات الإيقاع الحيوي لمرحلة الربع نهائي لأولمبياد ريو

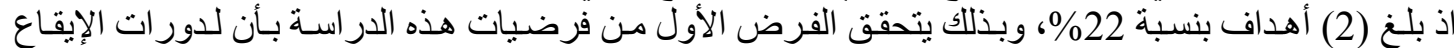

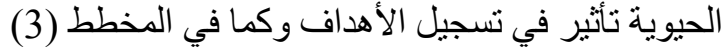

\section{مخطط (3) موراته (3)}

توضيح نسبة مشاركة الها/فين في معدل دوراتهم الحيوية للدور ربع نهائي أولمبياد ريو 2016

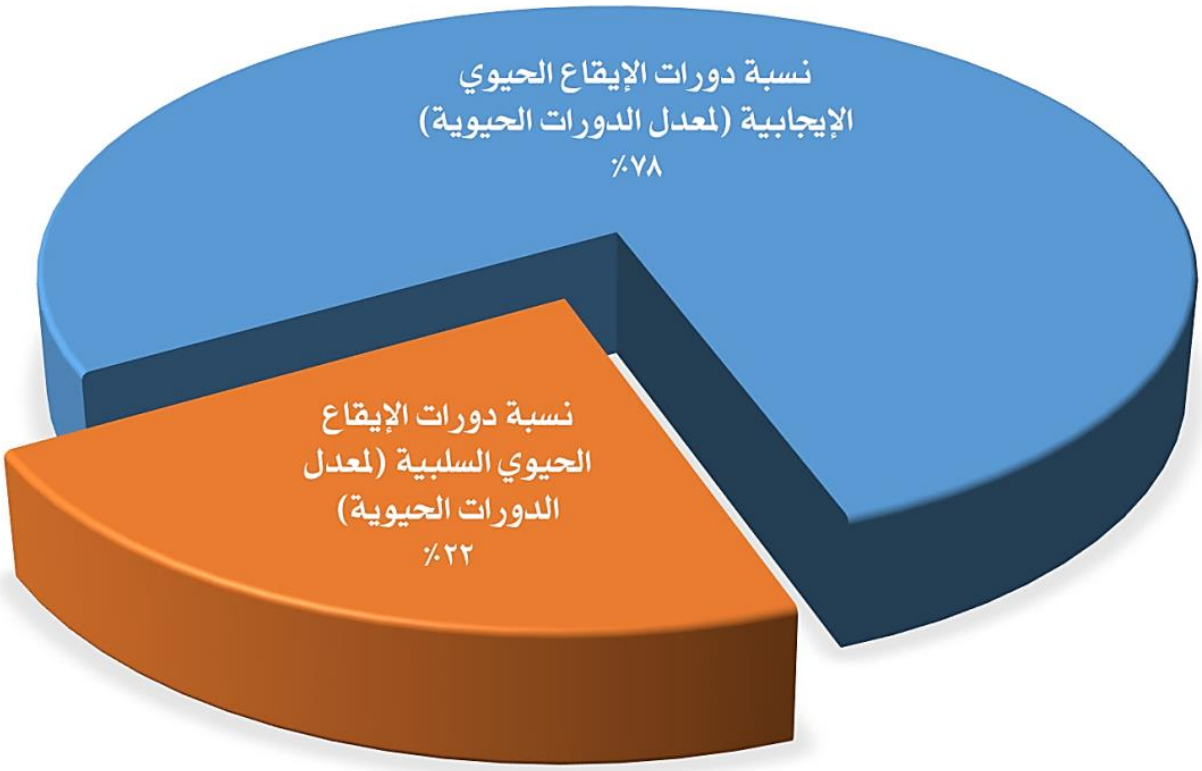

6. عرض وتحليل مرحلة النصف نهائي من بطولة أولمبياد ريو 2016.

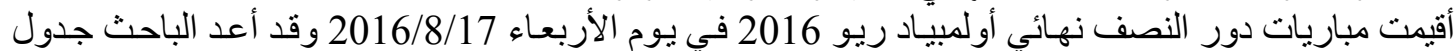

بأسماء الهدافين لهذا الدور مع قيم دور اتهم الحيوية الثلاثة ومعدل تللك الدور الأبعات وكما في الجدول (6). 


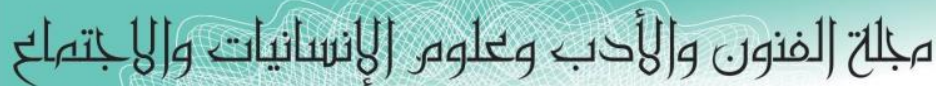
Journal of Arts, Literature, Humanities and Social Sciences

ISSN online: 2414 - 3383

ISSN print: 2616 - 3810

\section{العدد (4O) توز - يوليو 2019}

جدول (6) (20)

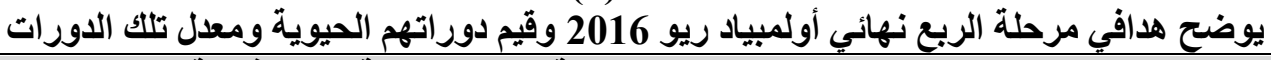

\begin{tabular}{|c|c|c|c|c|c|c|c|}
\hline المنتخب & المعدل & الذهنية & النفسية & البانية & مركز اللعب & عدد الاهداف & الاسم \\
\hline ألمانيا & $\% 63$ & $\% 76$ & $\% 100$ & $\% 14$ & مهاجم & 1 & نيل بترسين \\
\hline البر ازيل & $\% 56$ & $\% 95$ & $\% 0$ & $\% 73$ & وسط & 1 & والاس أوليفرا \\
\hline البر ازيل & $\% 37$ & $\% 62$ & $\% 62$ & $\% 14$ & دفاع & 1 & ماركوس كوريا \\
\hline البر ازيل & $\% 12-$ & $\% 87$ & $\% 97-$ & $\% 27-$ & مهاجم & 2 & غابرييل خيسوس \\
\hline البر ازيل & $\% 17$ & $\% 10$ & $\% 0$ & $\% 40$ & مهاجم & 2 & نيمار دي سليفا \\
\hline \multirow[t]{2}{*}{ ألمانيا } & \multirow[t]{2}{*}{$\% 38-$} & \multirow[t]{2}{*}{$\% 87$} & \multirow[t]{2}{*}{$\% 100-$} & \multirow[t]{2}{*}{$\% 100-$} & \multirow[t]{2}{*}{ دفاع } & 1 & لوكاس كلوستمان \\
\hline & & & & & & 8 & المجموع \\
\hline
\end{tabular}

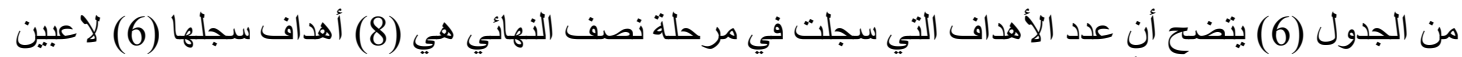

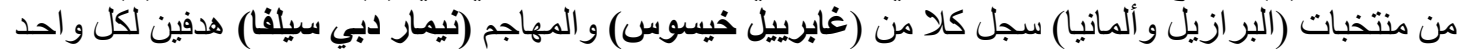

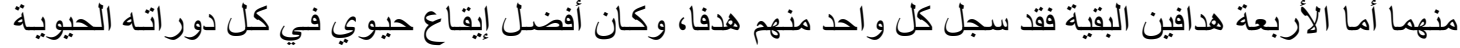
للاعب (نيل بترسين) و الذي حقق تفوقا في دورته البدنية التي بلغت 63 \%

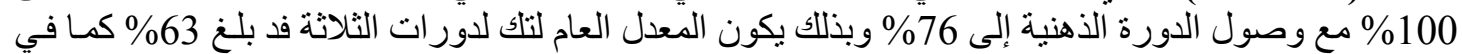

المخطط (4).

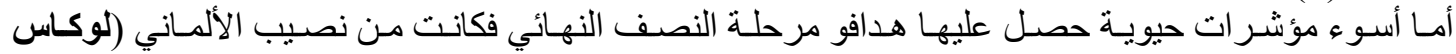

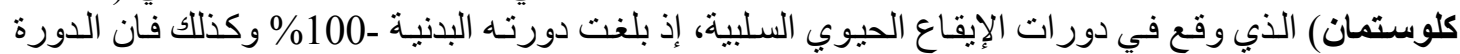

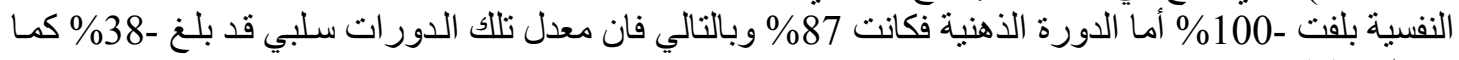

\section{(4) مخطط}

في المخطط (4). (1) (1)

توضيح نسبة مشاركة الها|فين في معدل دوراتهم الحيوية للاور ربع نهائي أولمبياد ريو 2016

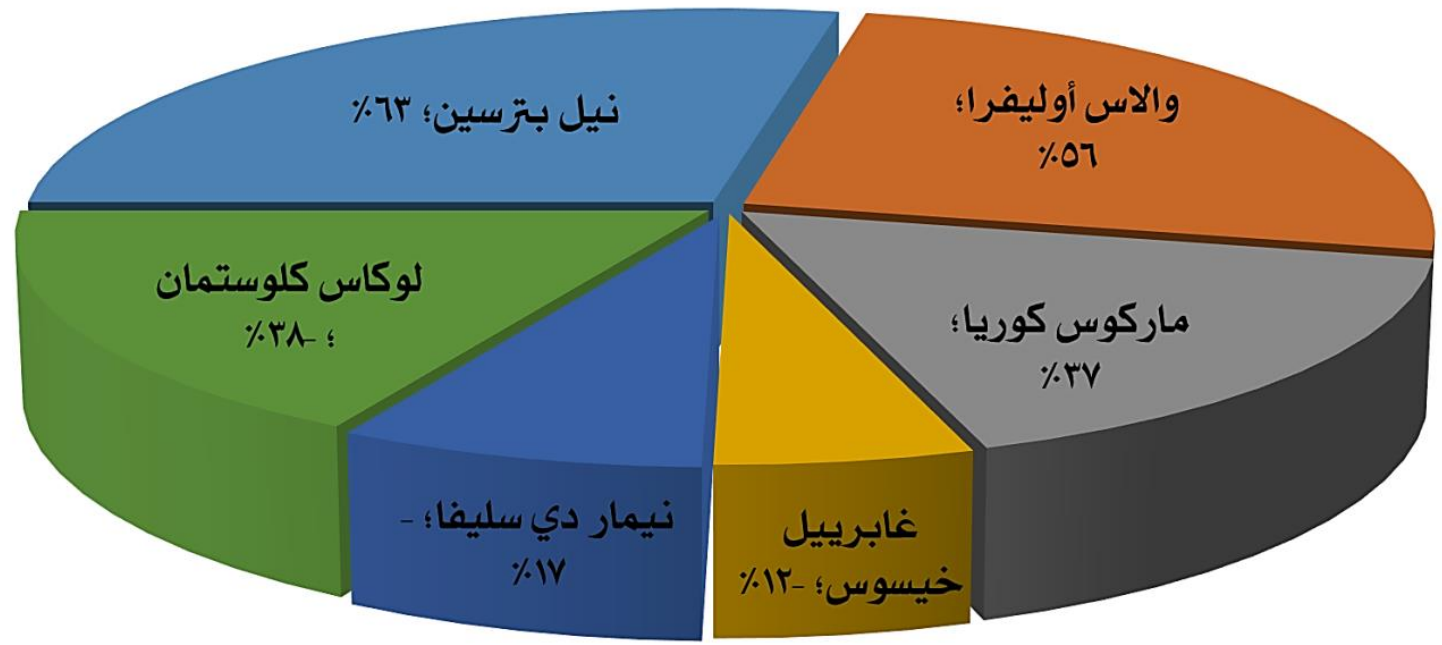

7. عرض الوسط الحسابي والانحر اف المعياري للمرحلة الريع نهائي من بطولة أولمبياد ريو 2016.

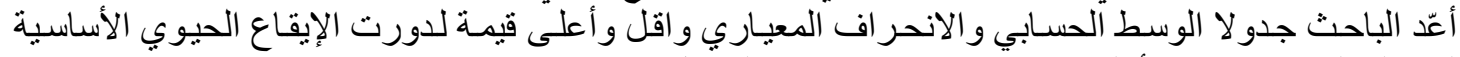
لمرحلة الربع نهائي من أولمبياد ريو 2016. وكما في الجي الجدول (7). 


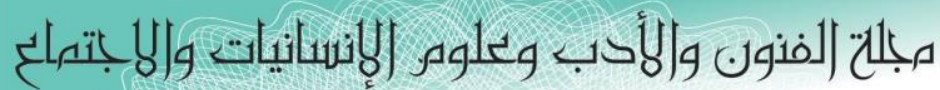

Journal of Arts, Literature, Humanities and Social Sciences

ISSN online: 2414 - 3383

ISSN print: 2616 - 3810

\section{العدد (4O) تموز - يوليو 2019}

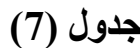

الوسط الحسابي والاتحر اف المعياري واقل وأعلى قيمة لدورت الإيقاع الحيوي الأساسية للربع نهائي من أولمبياد ريو 2016

\begin{tabular}{|c|c|c|c|c|c|}
\hline المعدل & الذهنية & النفسية & البدنية & الأهداف & \\
\hline 8 & 8 & 8 & 8 & 8 & عدد الأهداف \\
\hline 7.50 & 59.25 & $16.50-$ & $20.13-$ & & الوسط الحسابي \\
\hline 38.42 & 43.86 & 76.05 & 49.48 & & \\
\hline $\begin{array}{c}\% 38- \\
\% 83\end{array}$ & $\begin{array}{c}\% 10- \\
\% 73\end{array}$ & $\begin{array}{l}\% 100- \\
\% 100\end{array}$ & $\begin{array}{c}\% 100- \\
\% 95\end{array}$ & & \\
\hline
\end{tabular}

8. عرض نسبة المعدل العام لاورات الإيقاع الحيوي لأفضل اول ثلاثة لاعبين في مرحلة الربع نهائي من

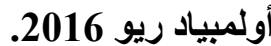
اعد الباحث جدو لا يتضمن أفضل الإيقاعات الحيوية لأفضل ثلاثة هدافين في مرحلة الربع نهائي من أولمبياد ريو

جدول (8) (8) (2)

2016 وكما في الجدول (8).

يوضح دورات الإيقاع الحيوي لأفضل هدافي مرحلة الربع نهائي من أولمبياد رو 2016

\begin{tabular}{|c|c|c|c|}
\hline المنتخب & المعدل العام للادورات & مركز اللعب & الاسم \\
\hline ألمانيا & $\% 63$ & مهاجم & نيل بترسين \\
\hline البر ازيل & $\% 56$ & وسط & و الاس أوليفرا \\
\hline البر ازيل & $\% 37$ & دفاع & ماركوس كوريا \\
\hline
\end{tabular}

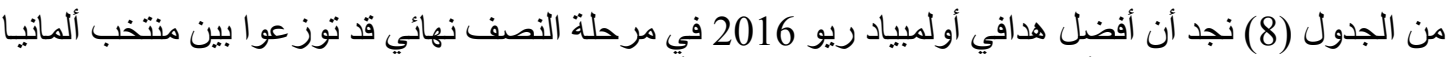

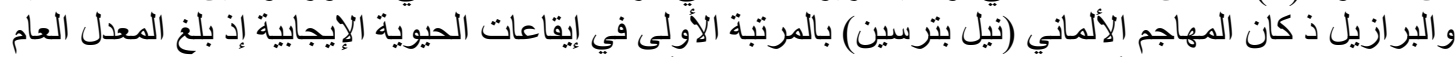

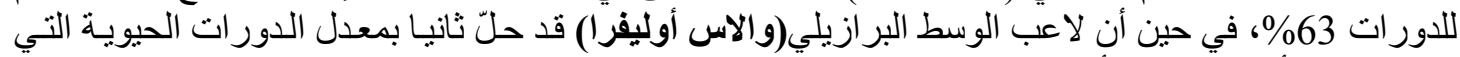

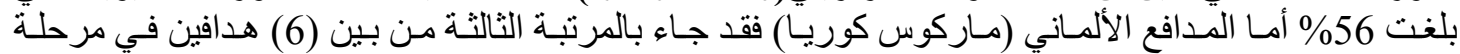

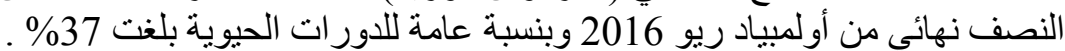

9. عرض نسبة دورات الإيقاع الحيوي للمنتخبات مرحلة النصف نهائي من بطولة أولئية المبياد ريو الإيو 2016. أعّد الباحث جدو لا يبين قيمة لدورت الإت الإيقاع الحيوي الأساسية للمنتخبات المشاركة في النصف نهائي المئي من أولمبياد

ريو 2016. وكما في الجدول (9).

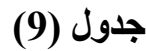

يوضح عدد الأهداف المسجلة نسبة إلى مراكز اللعب في أولمبياد ريو 2016

\begin{tabular}{|c|c|c|}
\hline النسبة المئوية & عدد الأهداف & المنتخبات \\
\hline$\% 75$ & 6 & البرازيل \\
\hline \multirow[t]{2}{*}{$\% 25$} & 2 & ألمانيا \\
\hline & 8 & المجموع \\
\hline
\end{tabular}

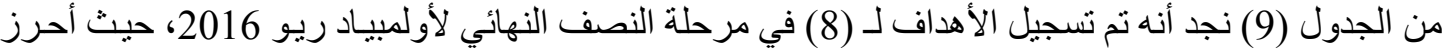

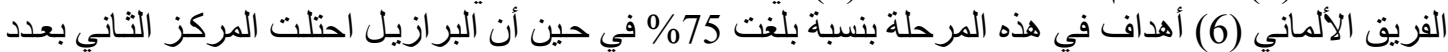

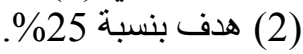




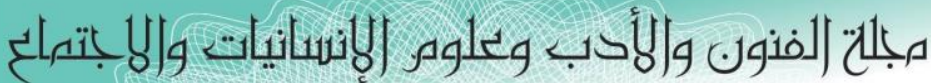

Journal of Arts, Literature, Humanities and Social Sciences

ISSN online: 2414 - 3383

ISSN print: 2616 - 3810

\section{العدد (4O) تموز - يوليو 2019}

10. عرض مستويات دورات الإيقاع الحيوي الايجابية لنصف نهائي من بطولة أولمبياد ريو 2016.

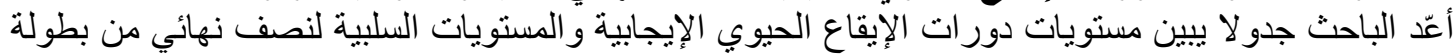
أولمبياد ريو 2016 وكما في الجدول (10).

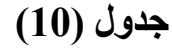

يوضح مستويات الإيقاع الحيوي الإيجابية والسلبية لهدافي النصف النهائي من أولمبياد ريو 2016

\begin{tabular}{|c|c|c|}
\hline النسبة المئوية & عدد اللاعبين & مستوى معدل دورات الإيقاع الحيوي \\
\hline$\% 50$ & 3 & المستوى الإيجابي لمعدل الدورات الحيوية \\
\hline$\% 50$ & 3 & المستوى السلبي لَمعدل الدورات الحيوية \\
\hline$\% 100$ & 6 & 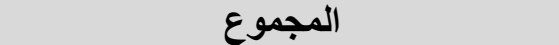 \\
\hline
\end{tabular}

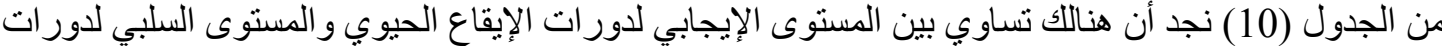

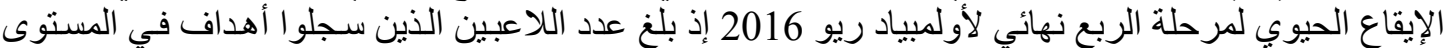

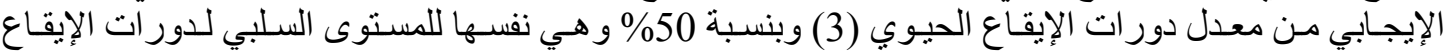

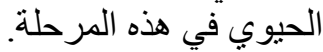

11. عرض وتحليل مرحلة النصف نهائي من بطولة أولمبياد ريو 2016.

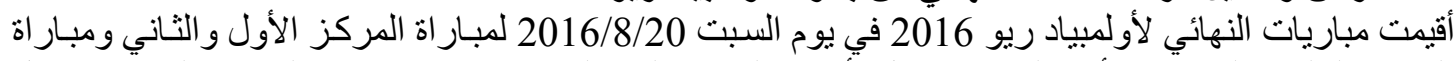

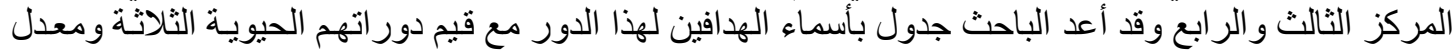

تلالك الدور ات وكما في الجدول (11).

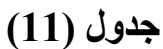

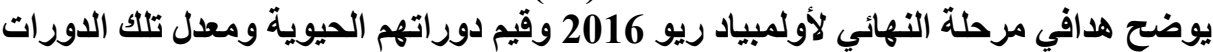

\begin{tabular}{|c|c|c|c|c|c|c|c|}
\hline المنتخب & المعدل & الأهنية & النفسية & البدنية & مركز اللعب & عدد الأهداف & 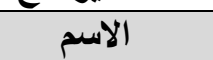 \\
\hline & & & & & \multicolumn{3}{|c|}{ المباراة النهائية (المركز الثالث والرابع) } \\
\hline نيجريا & $\% 43$ & $\% 87$ & $\% 22-$ & $\% 63$ & 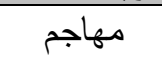 & 2 & صادق عمر \\
\hline نيجريا & $\% 50$ & $\% 10$ & $\% 43-$ & $\% 98$ & 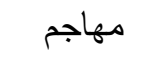 & 1 & أمينو عمر \\
\hline 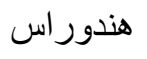 & $\% 39$ & $\% 19$ & $\% 0$ & $\% 98$ & 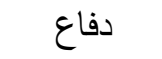 & 1 & مارسلوبيريرا \\
\hline \multirow[t]{2}{*}{ 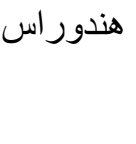 } & $\% 83$ & $\% 69$ & $\% 97$ & $\% 82$ & 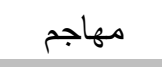 & 1 & أنتوني لوزانو \\
\hline & & & & & \multicolumn{3}{|c|}{ المباراة النهائية (المركز الأول والثاني) } \\
\hline ألبرانيا & $\begin{array}{c}\% 31- \\
\% 4\end{array}$ & $\begin{array}{l}\% 62- \\
\% 46-\end{array}$ & $\begin{array}{l}\% 62 \\
\% 43-\end{array}$ & $\begin{array}{l}\% 94- \\
\% 100\end{array}$ & مهاجم & $\begin{array}{l}1 \\
1\end{array}$ & نيمار دي سليفا \\
\hline
\end{tabular}

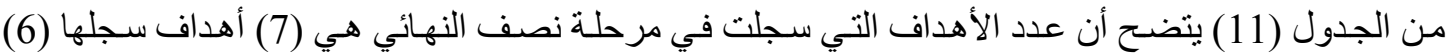

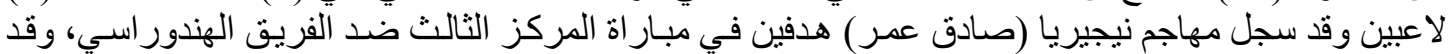

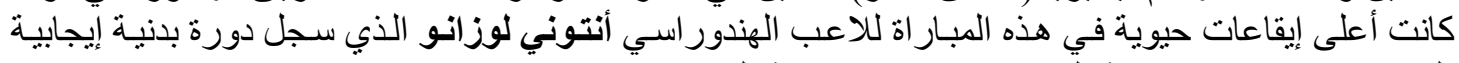

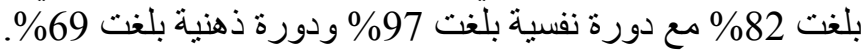




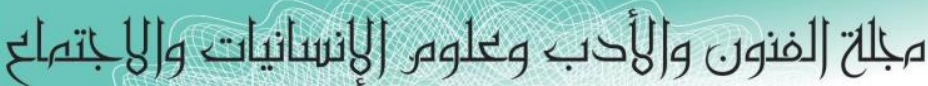

Journal of Arts, Literature, Humanities and Social Sciences

ISSN online: 2414 - 3383

ISSN print: 2616 - 3810

\section{العدد (4O) توز - يوليو 2019}

أما بالنسبة إلى مبار اة المركز الأول والثاني من نهائيات أولمبياد ريو 2016 فقد انتهت بتعـادل الفريقين ألماني

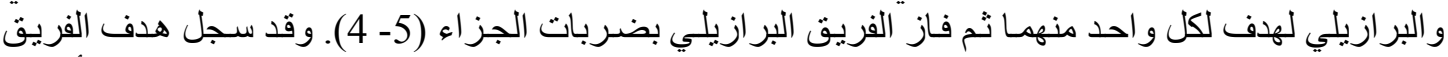

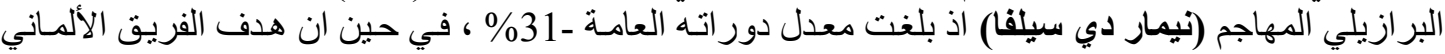

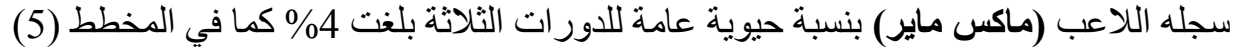

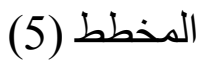

يوضح نسبة مشاركة الهذافين في معدل دوراتهم الحيوية للاور انهائي من أولمبياد ريو 2016

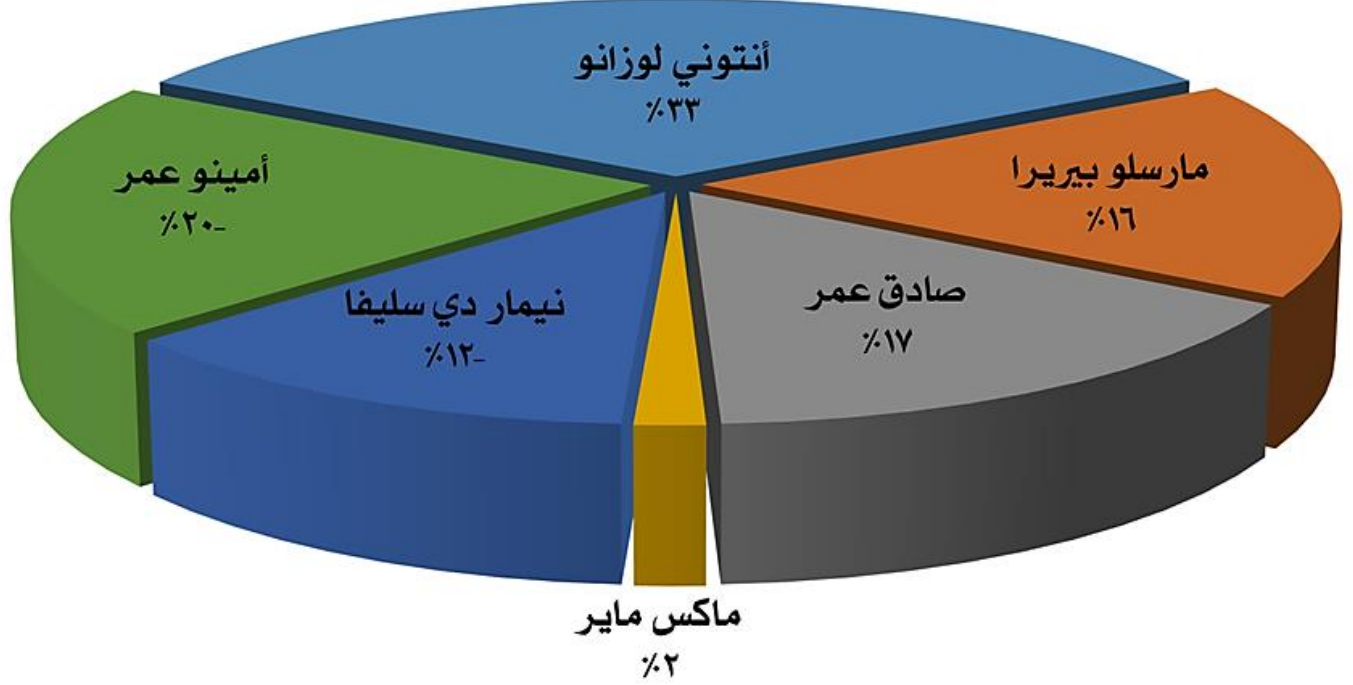

12. عرض مستويات دورات الإيقاع الحيوي الايجابية والسلبية لنهائي أولمبياد ريو 2016.

أعّد الباحث جدولا يبين مستويات دورات الإيقاع الحيوي الإيجابية والمستويات السلبية لنهائي أولمبياد ريو

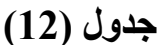

2016 وكما في الجدول (12).

يوضح مستويات الإيقاع الحيوي الإيجابية والسلبية لهدافي النهائي من أولمبياد ريو 2016

\begin{tabular}{|c|c|c|}
\hline النسبة المئوية & عدد اللاعبين & مستوى معدل دور ات الإيقاع الحيوي \\
\hline$\% 67$ & 4 & المستوى الإيجابي لمعدل الدورات الحيوية \\
\hline$\% 33$ & 2 & المستوى السلبي لمعدل الدورات الحيوية \\
\hline$\% 100$ & 6 & المجموع \\
\hline
\end{tabular}

من الجدول (12) نجد أن هنالك تساوي بين المستوى الإيجابي لدور ات الإيقاع الحيوي و المستوى السلبي لدور اتلات

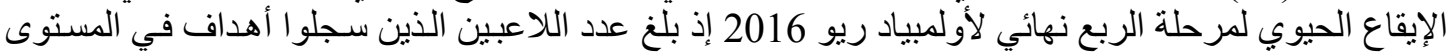

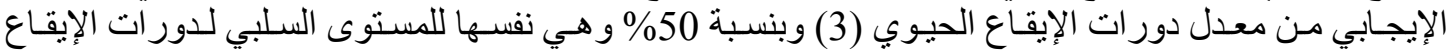
الحيوي في هذه المرحلة. 


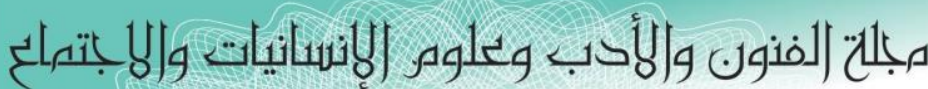

Journal of Arts, Literature, Humanities and Social Sciences

ISSN online: 2414 - 3383

ISSN print: 2616 - 3810

\section{العدد (4O) توز - يوليو 2019}

HALHSS

13. عرض وتحليل المراحل الثلاثة (ربع نهائي ونصف نهائي والنهائي) لبطولة أولمبياد ريو 2016.

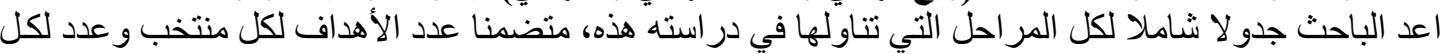

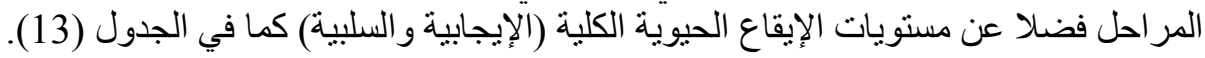

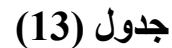

يوضح عدد الأهداف لكل منتخب وعدد لكل المراحل فضلا عن مستويات الإيقاع الحيوية الكلية (الإيجابية والسلبية).

\begin{tabular}{|c|c|c|c|c|}
\hline & النسبة المئوية & عدد الأهداف & 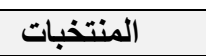 \\
\hline & & \%38 & 9 & 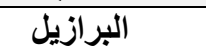 \\
\hline & & $\% 29$ & 7 & ألمانيا \\
\hline & & $\% 21$ & 5 & نيجريا \\
\hline & & $\% 12$ & 3 & هندور اس \\
\hline & & $\% .100$ & 24 & المجموع \\
\hline & النسبة المئوية & عدد الأهداف & المباريات & الأدوار \\
\hline & $\% 38$ & 9 & 4 & الربع نهائي \\
\hline & $\% 33$ & 8 & 2 & النصف نهائي \\
\hline & $\% 29$ & 7 & 2 & النهائي \\
\hline & $\% .100$ & 24 & 8 & المجموع \\
\hline \multicolumn{2}{|c|}{ النسبة المئوية } & الهدافين & \multicolumn{2}{|c|}{ مستوى معدل دورات الإيقاع الحيوي } \\
\hline \multicolumn{2}{|c|}{$\% 67$} & 14 & \multicolumn{2}{|c|}{ المستوى الإيجابي لمعدل الدورات الحيوية } \\
\hline \multicolumn{2}{|l|}{$\% 33$} & 7 & \multicolumn{2}{|c|}{ المستوى الإلبجبي لمعدل الدورات الحيويةً } \\
\hline \multicolumn{2}{|l|}{$\% 100$} & 21 & \multicolumn{2}{|c|}{ المجموع } \\
\hline
\end{tabular}

من الجدول (13) يتضح أن عدد هدافي هذه المر احل التي تتناولتها هذه الدراسة قد بلغ (21) هدافا سجلو العددا من

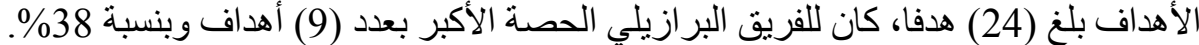

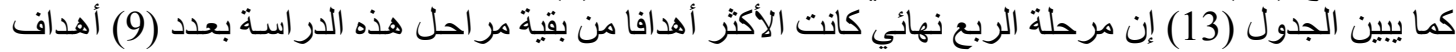

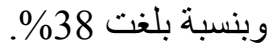

كما بين الجدول (13) أن المستويات الإيجابيـة لمعدل دور ات الإيقـاع الحيوي الأساسية (الذهنيـة ـ النفسبة ـ

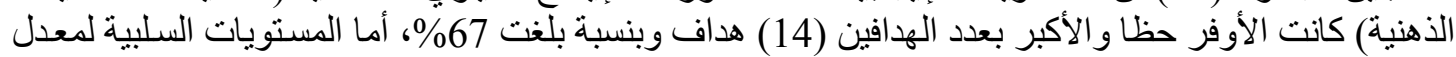

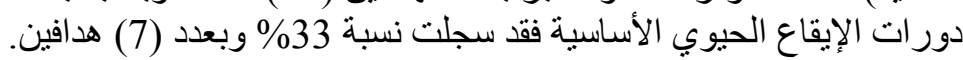

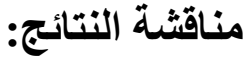
- نجد في الجدول (1) أن عدد اللاعبين الذين سجلوا أهداف في مرحلة الربع نهائي و الذين كانو ا في المستوى

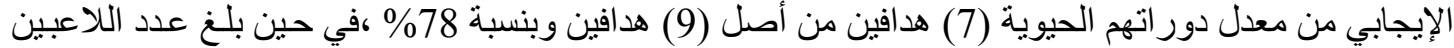
الذين وقعو ا في المستوى السلبي من معدل دور ات الإيقاع الحيوي فقد بلغ (2) هدافين من العدد الكلي (9) هدافين

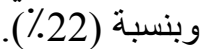

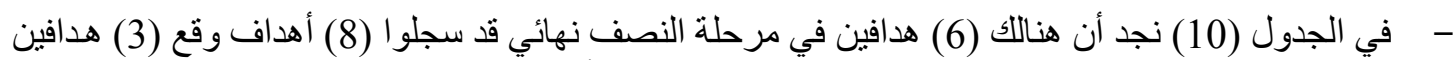

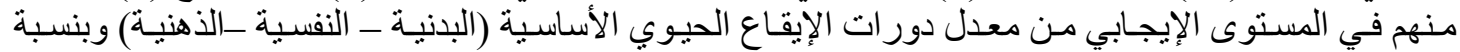

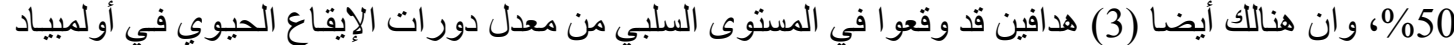
ريو دي جانيرو 2016 وبنسبة 50\%.

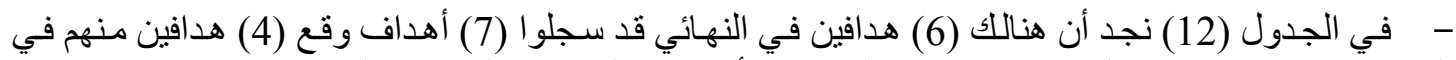

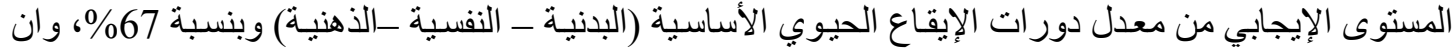




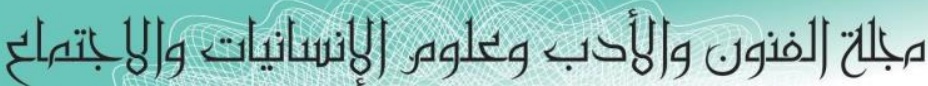

Journal of Arts, Literature, Humanities and Social Sciences

ISSN online: 2414 - 3383

ISSN print: 2616 - 3810

\section{العدد (4O) توز - يوليو 2019}

هنالك أيضا (2) هدافين قد وقعوا في المستوى السلبي من معدل دور ات الإيقاع الحيوي في أولمبياد ريو دي

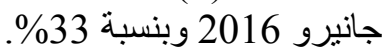

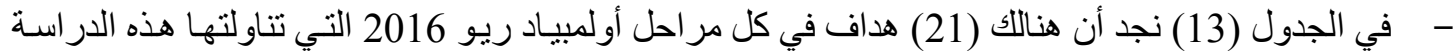

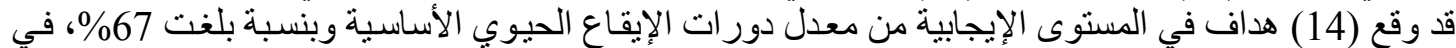

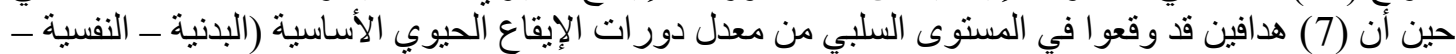

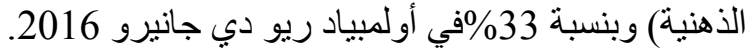

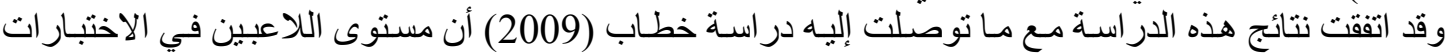

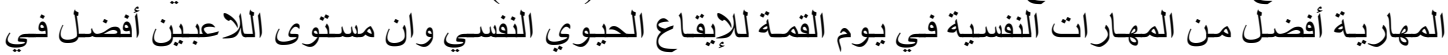

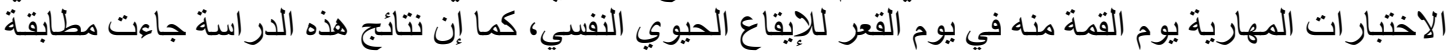

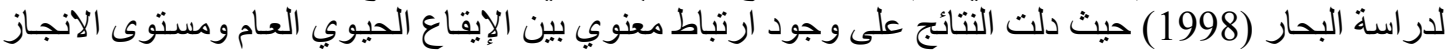

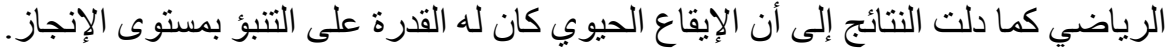

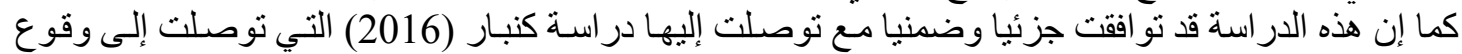

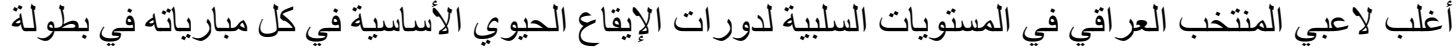

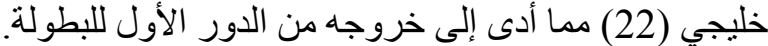

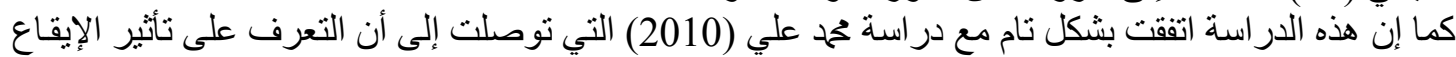

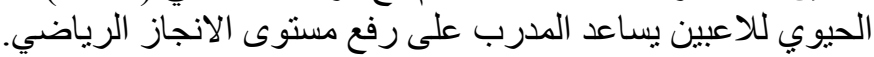

الاستنتاجاث

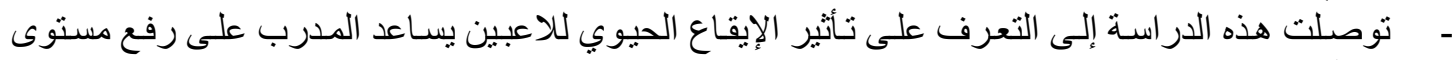

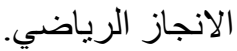

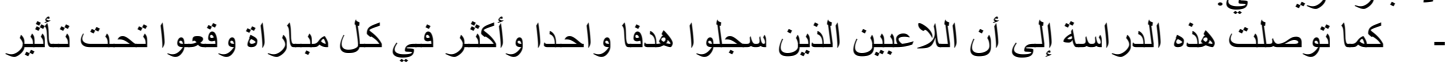

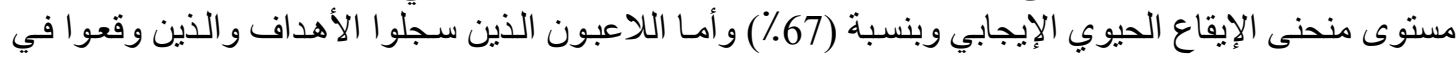

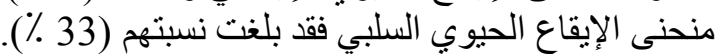

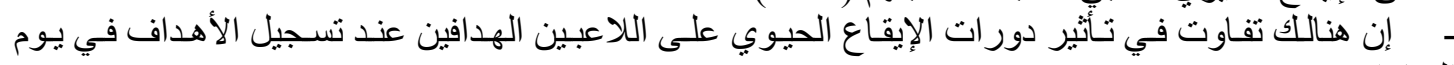
المبار اة.

التوصباث:

توصي هذه الدراسة بضرورة مشاركة اللاعبين الذين هم على الجانب الإيجابي من الإيقاع الحيوي في التشكيلة

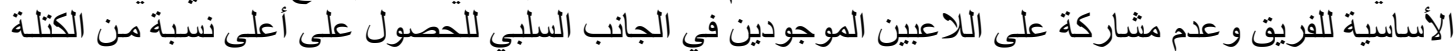
الحيوية للفريق خلال المبار اة.

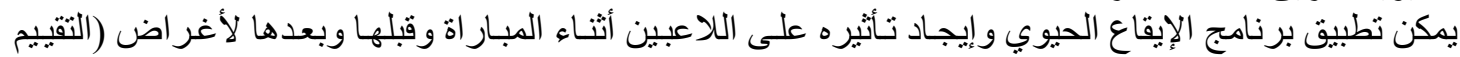

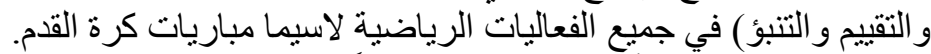

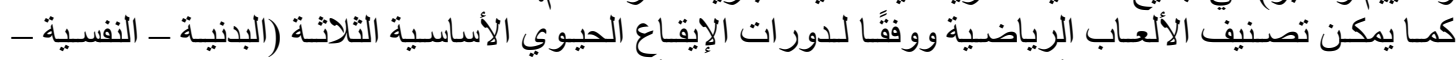

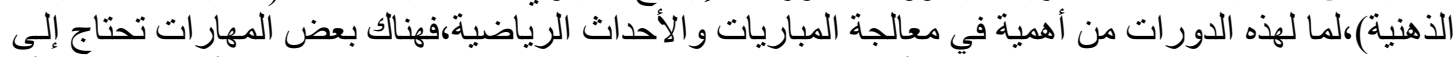

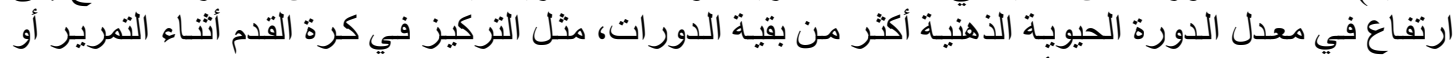

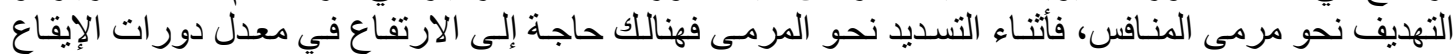

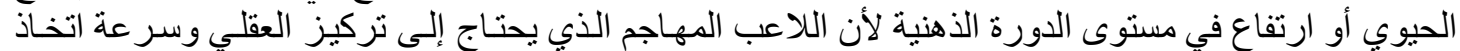

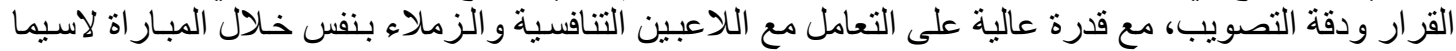

لحظة تسديد الكرة نحو مرمى المنافس لتحقيق هدف.

1المراجـع البحار،ياسمين حسن (1998) علاقة الإيقاع الحيوي بمستوى الانجاز الرياضي للاعبات الجمباز

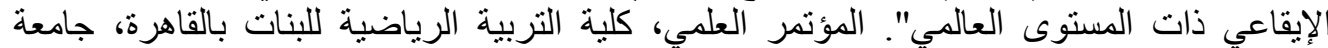
حلو ان،مصر. 


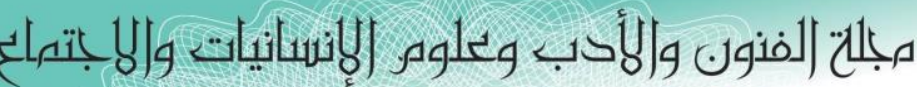

Journal of Arts, Literature, Humanities and Social Sciences

ISSN online: 2414 - 3383

ISSN print: 2616 - 3810

2. البيك،على فهمي وعمر،صبري (1994) :الإيقاع الحيوي والإنجاز الرياضي ـ منشأة المعارف

3. إبراهيم، أحمد محمود(1995): مبـادئ التخطيط للبرامج التعليميـة والتدريبية، رياضة الكاراتيه، منشأة المعارف، الإسكندرية، مصر.

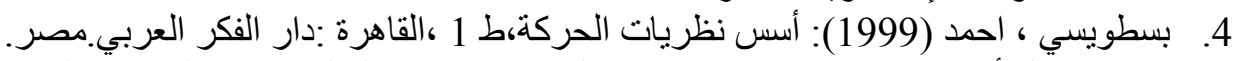

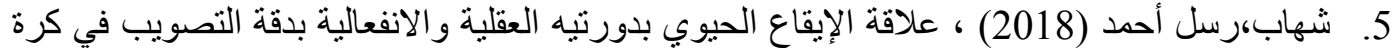

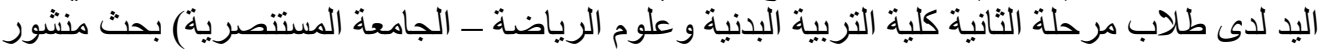

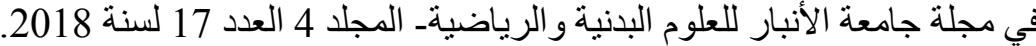

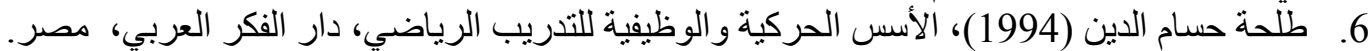

7.

(22) وفقاً للإيقاع الحيوي للاعبين) بحث رقم (1988) منشور في مجلة العلوم التربوية والنية النفسية

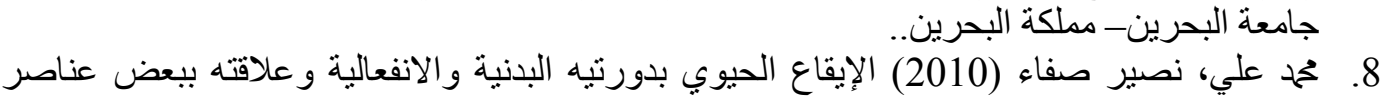

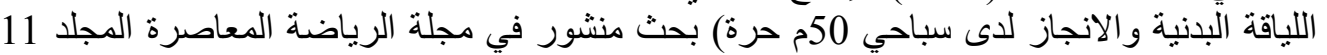

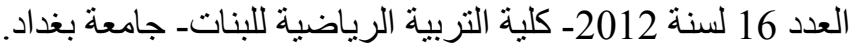

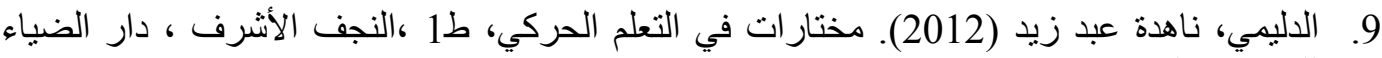

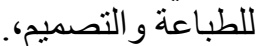

10. خيون، يعرب (2002) التعلم الحركي بين النظرية و التطبيق ،بغداد : مكتب الصخرة للطباعة.

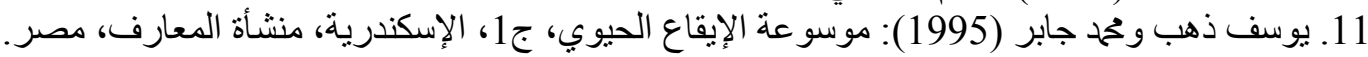

